\title{
ARTICLE
}

\section{Inhibition of IL-1R1/MyD88 signalling promotes mesenchymal stem cell-driven tissue regeneration}

\author{
Mikaël M. Martino', Kenta Maruyama', Gisela A. Kuhn², Takashi Satoh', Osamu Takeuchi',3, Ralph Müller ${ }^{2}$ \& \\ Shizuo Akira ${ }^{1}$
}

Tissue injury and the healing response lead to the release of endogenous danger signals including Toll-like receptor (TLR) and interleukin-1 receptor, type 1 (IL-1R1) ligands, which modulate the immune microenvironment. Because TLRs and IL-1R1 have been shown to influence the repair process of various tissues, we explored their role during bone regeneration, seeking to design regenerative strategies integrating a control of their signalling. Here we show that IL-1R1/MyD88 signalling negatively regulates bone regeneration, in the mouse. Furthermore, IL-1 $1 \beta$ which is released at the bone injury site, inhibits the regenerative capacities of mesenchymal stem cells (MSCs). Mechanistically, IL-1R1/MyD88 signalling impairs MSC proliferation, migration and differentiation by inhibiting the Akt/GSK-3 $\beta / \beta$-catenin pathway. Lastly, as a proof of concept, we engineer a MSC delivery system integrating inhibitors of IL-1R1/MyD88 signalling. Using this strategy, we considerably improve MSC-based bone regeneration in the mouse, demonstrating that this approach may be useful in regenerative medicine applications.

\footnotetext{
${ }^{1}$ WPI Immunology Frontier Research Center, Osaka University, 3-1 Yamada-oka, Suita, Osaka 565-0871, Japan. ${ }^{2}$ Institute for Biomechanics, Leopold-Ruzicka-Weg 4, ETH Zurich, Zurich 8093, Switzerland. ${ }^{3}$ Institute for Virus Research, Kyoto University, 53 Shogoin Kawara-cho, Sakyo-ku, Kyoto 606-8507, Japan. Correspondence and requests for materials should be addressed to M.M.M. (email: mmartino@ifrec.osaka-u.ac.jp) or to S.A. (email: sakira@biken.osaka-u.ac.jp).
} 
A lthough, the advancement of regenerative medicine will play a vital role in meeting the future healthcare challenges, the promises of regenerative therapies remain largely unrealized. For designing effective regenerative medicine strategies, we should better understand the interactions between the multiple actors that shape a regenerative environment. In particular, tissue injury is generally associated with an immune response, which is most likely a key regulator of the healing process $^{1,2}$. Hence, in-depth understanding of the role of the immune system during tissue repair and regeneration could provide clues to therapeutic avenues for restoring damaged tissues, and controlling the immune regulations of tissue healing may become an attractive option in regenerative medicine ${ }^{1,2}$.

Unlike most tissues, bone possesses an innate capacity to regenerate following injury. The majority of bony injuries, when properly treated by re-apposition, heal without a permanent lesion. However, many clinical indications remain that require therapeutic intervention to augment bone regeneration such as large craniomaxillofacial defects, bone degeneration in patients with osteonecrosis, distal tibial fractures and periodontal disease $^{3,4}$. Autologous bone grafting is currently the gold standard, but this approach is associated with numerous drawbacks, including donor-site morbidity, the availability of limited grafting material and compromised bone quality in patients with osteoporosis ${ }^{5}$. Therefore, extensive efforts have been made to develop bone regenerative strategies using various combinations of cells ${ }^{4}$, growth factors ${ }^{6}$ and biomaterials ${ }^{7}$. However, only few of these strategies have translated into clinical practice and none of them have become a standard in regenerative medicine. Efficacy, safety, practical, costeffectiveness and regulatory issues often prevent the widespread therapeutic use of bone regenerative therapies ${ }^{4,8}$. In addition, one of the major challenges lies in the limited understanding of the cellular and molecular mechanisms that should be targeted to promote bone regeneration. Especially, understanding and subsequently controlling the immune regulations of bone regeneration could be crucial to improve the effectiveness of bone regenerative therapies ${ }^{1,2,9}$.

Commonly, tissue injury and the healing response lead to the release of various endogenous danger signals including Toll-like receptor (TLR) and interleukin-1 receptor, type 1 (IL-1R1) ligands ${ }^{10,11}$, which modulate the immune microenvironment. These danger signals are involved in the recruitment and the activation of immune cells engaged in host defence ${ }^{11,12}$. In addition, TLRs and IL-1R1 have been shown to influence the repair process of several tissues ${ }^{13-23}$. For example, the injury promoting effects of TLR4 is apparent in many organs, as seen by the protection of TLR4-mutant or -deficient mice after hepatic, renal, cardiac and cerebral ischemia reperfusion ${ }^{13-16,19}$. Similarly, IL-1R1 signalling critically regulates infarct healing ${ }^{17}$ and disruption of IL-1 signalling can improve the quality of wound healing ${ }^{18,21}$.

In this study, we explore the role of TLRs and IL-1R1 during bone regeneration, seeking to design regenerative strategies integrating a control of their signalling. We show that IL-1R1 signalling via the adaptor protein MyD88 negatively regulates bone regeneration, in the mouse. IL-1 $\beta$ is released at the bone injury site and inhibits the regenerative capacities of mesenchymal stem cells (MSCs). Mechanistically, IL-1R1/MyD88 signalling impairs MSC migration, proliferation and differentiation into osteoblasts, by inhibiting the Akt/GSK- $3 \beta / \beta$-catenin pathway. Furthermore, we propose a MSC delivery system integrating inhibitors of IL-1R1/MyD88 signalling. Using this approach, we significantly improve MSC-based bone regeneration in a mouse critical size calvarial defect model, demonstrating that this approach may be useful in regenerative medicine applications.

\section{Results}

IL-1R1/MyD88 signalling negatively regulates bone regeneration. To evaluate the role of TLRs and IL-1R1 during bone regeneration, we first analysed regeneration in mice deficient for MyD88 and TRIF, which are key adaptor proteins involved in TLR and IL-1R1 signalling transduction ${ }^{12}$. Among the available orthotopic models used for evaluating bone regeneration, we chose the critical size calvarial defect, because this model have gained a widespread reputation and use in the published literature, reporting valuable data from basic and applied research ${ }^{24}$. Moreover, the critical size calvarial defect model is very reliable and displays low variability ${ }^{25}$, making it ideal to compare bone regeneration in multiple knockout mice. Critical size calvarial bone defects $(5 \mathrm{~mm}$ diameter) were created and filled with a standard fibrin matrix. The fibrin matrix was used to ensure clot formation in the defect and to standardize the model ${ }^{8}$, while the procedure did not significantly influence bone regeneration (Supplementary Fig. 1). Remarkably, 4 weeks post surgery, Myd88 $-1-$ mice displayed a faster regeneration characterized by a better coverage of the defect with mineralized bone (Fig. 1a,b), suggesting that TLR1, TLR2, TLR4-9, and/or IL-1R1 influence bone regeneration, since their signalling depends on MyD88 (ref. 12). When bone regeneration was analysed in $\operatorname{Tlr} 1^{-1-}, T l r 2 / 4 /$ $9^{-1-}$ (triple knockout), Tlr $5^{-1-}, T \operatorname{Tr} 7^{-1-}$ and $I l 1 r 1^{-I-}$ mice, only Illr1 $1^{-/-}$mice displayed better healing (Fig. 1c,d), indicating that IL-1R1/MyD88 signalling negatively regulates bone regeneration.

IL-1R1/MyD88 signalling inhibits MSC-driven bone regeneration. Since IL-1R1/MyD88 signalling is well known for inducing mobilization and activation of immune cells ${ }^{26}$, we determined whether this signalling inhibits bone regeneration by acting on the immune cells recruited after injury and throughout the regeneration process. As a model, we reconstituted lethally irradiated wild-type (wt) mice by intravenously injecting bone marrow cells from $M y d 88^{-/-}$mice, to have chimeric mice with bone marrow-derived immune cells unable to transduce IL-1R1/MyD88 signalling (Supplementary Fig. 2). While very few Myd88-1- bone marrow MSCs could have been transferred in

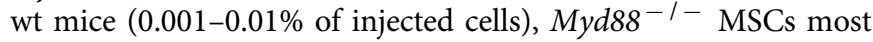
likely did not populate the bone marrow of irradiated wt mice, since the vast majority of MSCs does not go beyond lung and liver following intravenous injection ${ }^{27,28}$. Interestingly, $M y d 88^{-1}$

chimeric mice did not display better healing (Fig. 1e,f), suggesting that IL-1R1/MyD88 signalling negatively regulates bone regeneration by acting on tissue-resident cells. Since osteoclasts derive from bone marrow monocytes, they were lacking MyD88 in Myd88-1- chimeric mice. Therefore, we hypothesized that IL-1R1/MyD88 signalling negatively regulates bone regeneration by acting on osteoblasts and/or skeletal stem/progenitor cells including $\mathrm{MSCs}^{29-33}$.

To test whether IL-1R1/MyD88 signalling influences MSCdriven bone regeneration, we delivered syngeneic MSCs derived from bone of wt, $M y d 88^{-/-}$or $\operatorname{Illr} 1^{-/-}$mice into calvarial defects of wt mice, and we analysed regeneration after 4 weeks. MSCs from five isolates were pulled together and expended for three passages (Supplementary Fig. 3), before being delivered in bone defects through a fibrin matrix. Delivering wt MSCs resulted into a very slight improvement of regeneration compared with treatment without cells. In contrast, delivering $M y d 88^{-/-}$or Ill $r 1^{-1-}$ MSCs induced significantly better regeneration

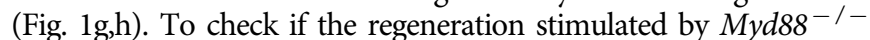
and Illr1 $1^{-/-}$MSCs relied on a better intrinsic capacity of these cells to differentiate towards osteoblasts or to proliferate, we compared them with wt MSCs in vitro. Without IL-1R1 ligands added to the cell culture medium, $M y d 88^{-/-}, I l 1 r 1^{-/-}$and wt 
a

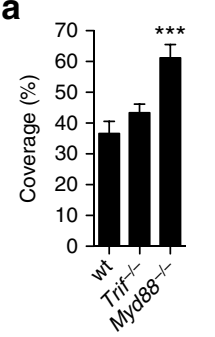

d

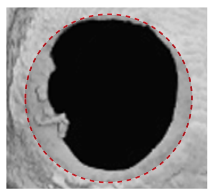

wt b
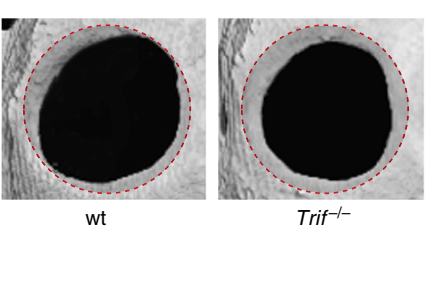

Trif $^{-/-}$

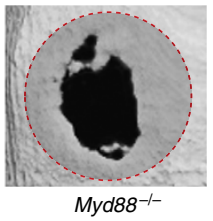

${\mathrm{Myd} 88^{-/-}}^{-1}$ c

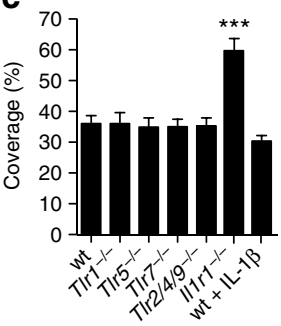

e

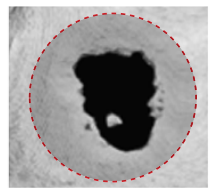

$1 / 1 r 1^{-1-}$

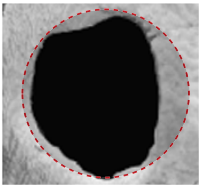

$w t+I L-1 \beta$

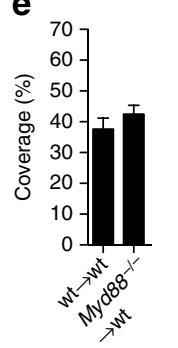

f

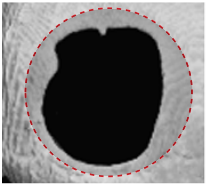

$\mathrm{wt} \rightarrow \mathrm{wt}$

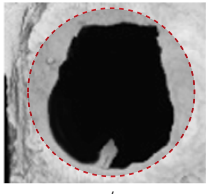

$\mathrm{Myd} 88^{-/-} \rightarrow \mathrm{wt}$

\section{g}

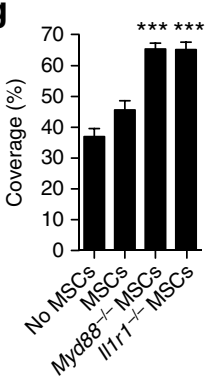

h

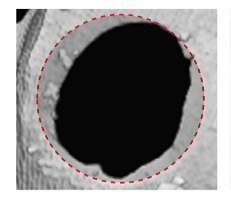

No MSCs

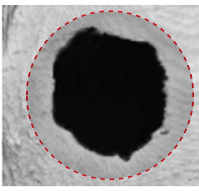

MSCs

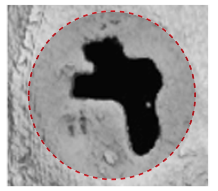

Myd88-1- MSCs

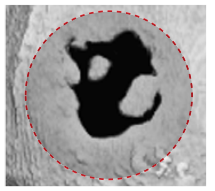

$111 \mathrm{r}^{-1-} \mathrm{MSCS}$

Figure 1 | IL-1R1/MyD88 signalling negatively regulates MSC-driven bone regeneration. Critical size calvarial defects ( $5 \mathrm{~mm}$ diameter) in mice were treated with a fibrin matrix. Four weeks after treatment, bone regeneration was measured by microCT as coverage of the defect. (a,b) Regeneration in wt,

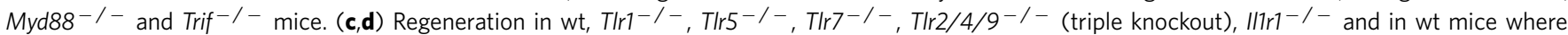
$10 \mathrm{ng}$ of IL-1 $\beta$ was co-delivered. (e,f) Regeneration in irradiated wt mice having received a bone marrow transplant from wt or $\mathrm{Myd}^{-1} 8^{-/-}$mice.

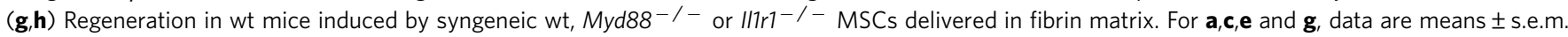
( $n \geq 6$ per condition). ANOVA with Bonferroni post hoc test for pair-wise comparisons; ${ }^{\star \star \star} P<0.001$. Representative calvarial reconstructions are shown in $\mathbf{b}$, $\mathbf{d}, \mathbf{f}$ and $\mathbf{h}$. Original defect area is shaded with a red dotted outline. ANOVA, analysis of variance.

a

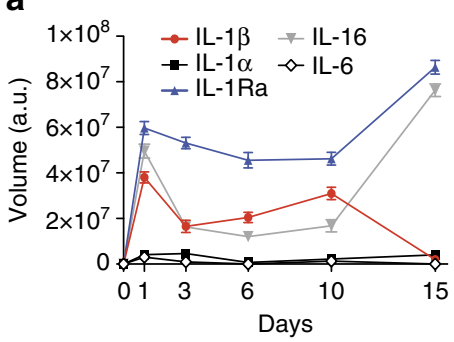

b

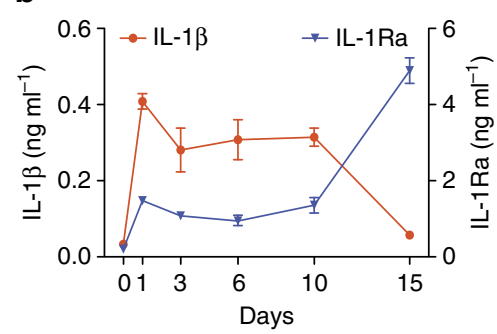

C

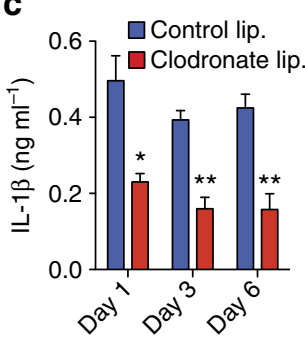

Figure 2 | IL-1 1 is present at a significant concentration in bone defects within the first $\mathbf{1 0}$ days following injury. (a-c) Calvarial defects ( $4 \mathrm{~mm}$ diameter) were treated with fibrin matrices. Fibrin matrices and bone tissue surrounding the defects ( $1 \mathrm{~mm}$ farther) were collected at different time points. Interleukins present in the harvested tissues and in fibrin matrices were detected using an antibody array (a) and by enzyme-linked immunosorbent assay $(\mathbf{b}, \mathbf{c})$. (c) IL-1 $\beta$ concentrations found in mice that have been treated with control or clodronate liposomes (lip.). For panels a-c, data are means \pm s.e.m. ( $n \geq 3$ per time point). ${ }^{\star} P<0.05,{ }^{\star \star} P<0.01$; Student's $t$-test.

MSCs showed equal ability to differentiate and to proliferate (Supplementary Fig. 4). Therefore, we hypothesized that the better regeneration induced by $M y d 88^{-/-}$and $I l 1 r 1^{-/-}$MSCs was due to their inability to sense IL-1R1 ligands present at the injury site.

IL-1 $\beta$ signalling via IL-1R1/MyD88 inhibits MSC functions. Using a cytokine array, we profiled the cytokines present in the bone defect microenvironment during the first 2 weeks following injury (Supplementary Fig. 5). Importantly, among IL-1R1 ligands $^{26}$, IL-1 $\beta$ as well as IL-1 receptor antagonist (IL-1Ra) were present at relatively high concentration within the first 10 days (Fig. 2a,b). After 10 days, IL-1 $\beta$ concentration starts to decline, while IL-1Ra concentration drastically increases afterwards, suggesting that the IL-1R1/MyD88 signalling occurs for at least 1 week post injury. Moreover, to gain insights about the cell types 
releasing IL-1 $\beta$, we quantified the concentration of the cytokine in calvarial defects of mice where monocytes/macrophages were depleted by clodronate liposomes ${ }^{34}$, since these cells are known to release a large amount of IL-1 $\beta$ (ref. 26). In mice depleted of monocytes/macrophages (Supplementary Fig. 6), the concentration of IL-1 $\beta$ was about twice lower during the first 6 days following injury (Fig. 2c), demonstrating that monocytes/ macrophages significantly contribute to the presence of IL- $1 \beta$.

Next, we explored the impact of IL-1R1/MyD88 signalling on the regenerative capacities of MSCs. We focused on colony formation, proliferation, migration, differentiation and trophic function (for example, secretion of growth factors), considering that these functions are critical for the regenerative potential of MSCs. When primary (uncultured) bone-derived MSCs were seeded in the presence of IL-1 $\beta\left(1 \mathrm{ng} \mathrm{ml}^{-1}\right)$, fibroblast colonyforming units (c.f.u.-F) and the average size of colonies were significantly lower (Fig. 3a,b; Supplementary Fig. 7a-c). In addition, IL-1 $\left(1 \mathrm{ng} \mathrm{ml}^{-1}\right)$ drastically inhibited the differentiation of the colonies towards osteoblasts (Fig. 3c; Supplementary Fig. $7 \mathrm{~d}$ ). Then, we analysed the effect of IL-1 $\beta$ on proliferation, migration, differentiation and trophic function, of bone-derived MSCs that have been expanded for three passages. Secretion of trophic factors from MSCs was not affected by IL-1 $\beta$ (Supplementary Fig. 8). Yet, IL-1 $\beta$ considerably inhibited MSC proliferation, when cells were co-stimulated with serum or with platelet-derived growth factor-BB (PDGF-BB), which is potent proliferation and migration factor for $\mathrm{MSCs}^{35}$ (Fig. 3d; Supplementary Fig. 9a). Similarly, transwell migration of MSCs towards serum or PDGF-BB was inhibited by IL-1 $\beta$ (Fig. 3e; Supplementary Fig. 9b). Regarding MSC differentiation, a single stimulation with a low concentration of $\mathrm{IL}-1 \beta(1 \mathrm{ng} \mathrm{ml}-1)$ severely inhibited their differentiation into osteoblasts (Fig. 3f,g; Supplementary Fig. 9c) and into chondrocytes (Supplementary Fig. 10). In addition, proliferation, migration and osteoblastic differentiation of MSCs lacking IL-1R1 and/or MyD88 were not affected by IL-1 $\beta$ (Supplementary Fig. 11), confirming that the IL-1R1/MyD88 signalling pathway is responsible for the inhibitory effects of the cytokine. Notably, IL-1 $\beta$ inhibited colony formation, proliferation, migration and osteoblastic differentiation of bone marrow-derived MSCs (Supplementary

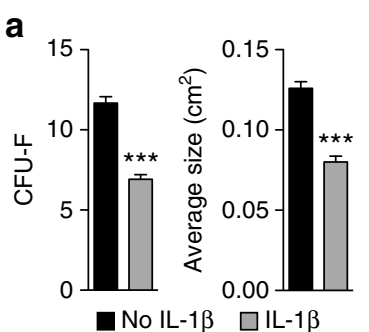

b

d

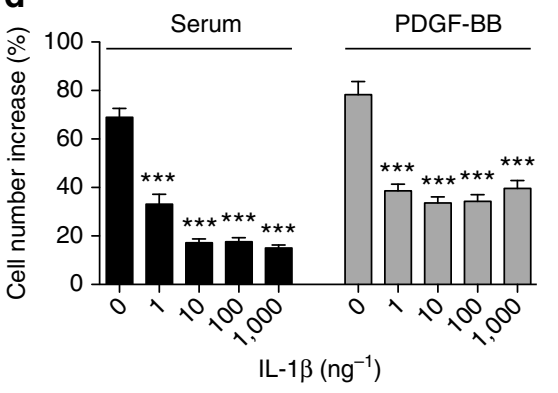

e

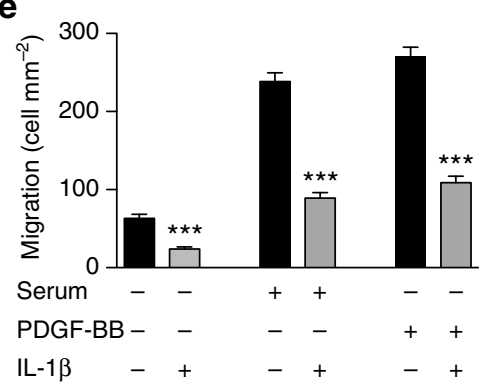

C

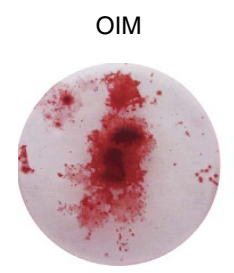

f
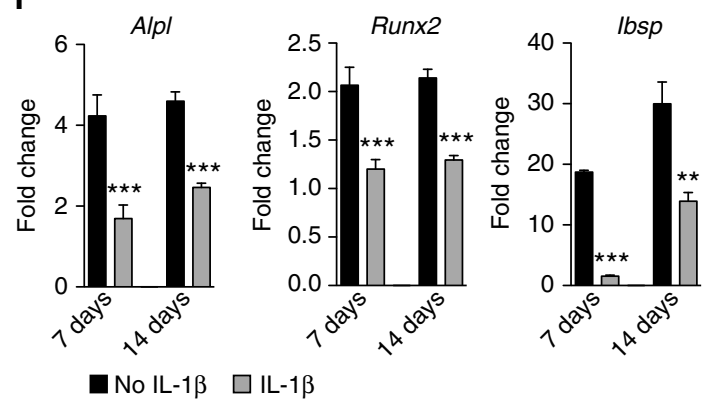

g
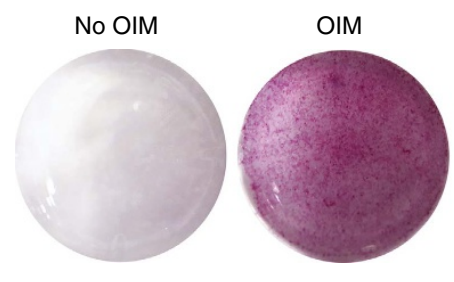

$\mathrm{OIM}+\mathrm{IL}-1 \beta$

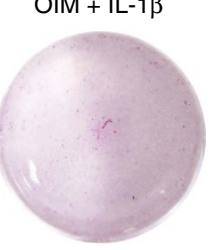

Figure 3 | IL-1 $\beta$ inhibits c.f.u.-F proliferation migration and osteoblastic differentiation of MSCs. (a,b) Primary MSCs were seeded with or without IL-1 $\beta$ $\left(1 \mathrm{ng} \mathrm{ml} \mathrm{m}^{-1}\right.$ during 6 days). Graphs show c.f.u. $-\mathrm{F}$ and average size of colonies. Data are means \pm s.e.m. $(n=6$ independent isolates). Representative wells $\left(9 \mathrm{~cm}^{2}\right.$ ) are shown in $\mathbf{b}$. (c) Primary MSCs were seeded in osteogenesis induction medium (OIM) for 28 days with or without IL-1 $3\left(1 \mathrm{ng} \mathrm{ml}{ }^{-1}\right.$ during 6 days). After 28 days, matrix mineralization was revealed with alizarin red staining. Representative wells are shown $\left(2 \mathrm{~cm}^{2}\right)$. (d) MSC proliferation was stimulated with $10 \%$ serum or PDGF-BB $\left(5 \mathrm{ng} \mathrm{ml}^{-1}\right)$, in the presence of IL-1 $\beta$ at increasing concentration. After $72 \mathrm{~h}$, cell number increase was measured. (e) Migration of MSCs through a transwell was induced by $10 \%$ serum or by PDGF-BB $\left(5 \mathrm{ng} \mathrm{ml}^{-1}\right)$, in the presence of IL-1 $\left(1 \mathrm{ng} \mathrm{ml}{ }^{-1}\right)$. After $6 \mathrm{~h}$, the number of cells per square millimetre that passed through the transwell was counted. (f) MSCs in OIM were treated once with IL-1 $1 \beta\left(1 \mathrm{ng} \mathrm{ml}^{-1} \mathrm{during} 4\right.$ days). After 7 and 14 days, expression of osteoblast-specific genes was determined by quantitative PCR. Fold changes in gene expression relative to MSCs cultured in normal medium are shown. Alpl, alkaline phosphatase; Runx2, runt-related transcription factor 2; Ibsp, integrin-binding sialoprotein. For $\mathbf{d}-\mathbf{f}$, data are means \pm s.e.m. $(n \geq 3)$. ${ }^{\star \star} P<0.01,{ }^{\star \star \star} P<0.001$; Student's $t$-test. $(\mathbf{g})$ MSCs in OIM were treated once with IL-1 $\beta\left(1 \mathrm{ng} \mathrm{ml}{ }^{-1}\right)$ during 4 days. After 28 days, matrix mineralization was revealed with alizarin red staining. Representative wells $\left(2 \mathrm{~cm}^{2}\right)$ are shown. 
a

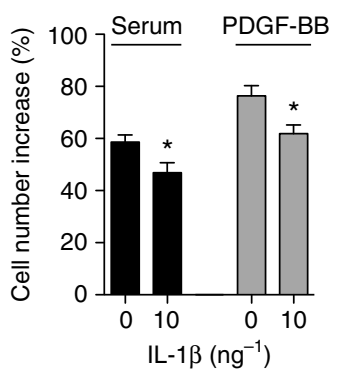

C

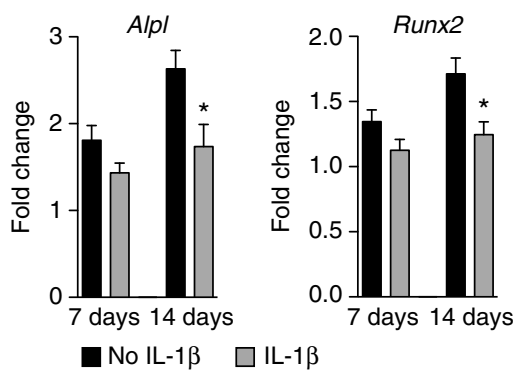

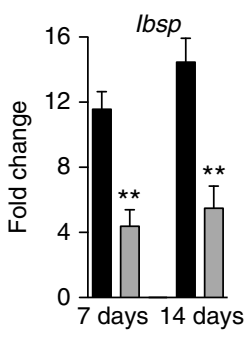

d
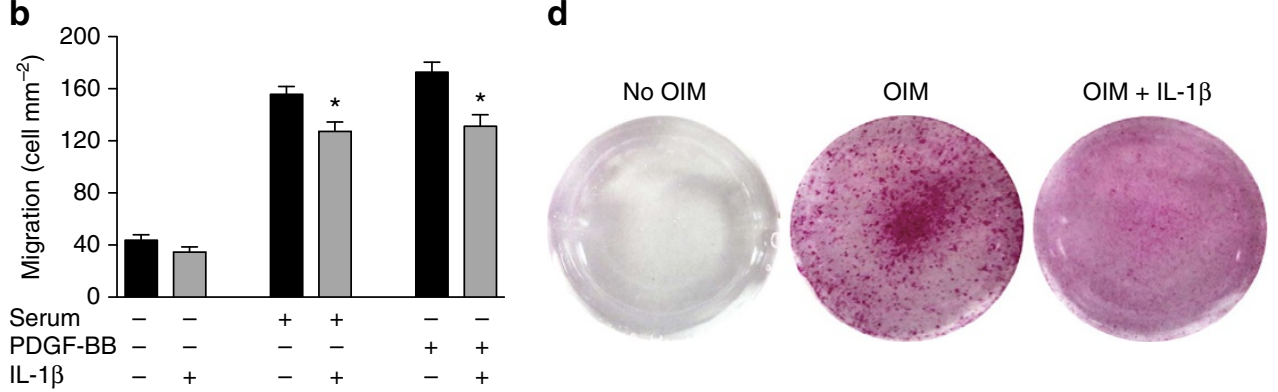

Figure 4 | IL-1ß slightly inhibits proliferation migration and differentiation of osteoblasts. (a) Osteoblast proliferation was stimulated with $10 \%$ serum or PDGF-BB $\left(10 \mathrm{ng} \mathrm{ml}^{-1}\right)$, in the presence of $5 \mathrm{ng} \mathrm{ml}^{-1}$ of IL-1 $\beta$. After $72 \mathrm{~h}$, the cell number increase was measured. Data are means $\pm \mathrm{s} . e . \mathrm{m}$. $(n=3)$. (b). Osteoblast migration through a transwell was induced by $10 \%$ serum or PDGF-BB $\left(5 \mathrm{ng} \mathrm{ml}^{-1}\right)$, in the presence of IL-1ß $\left(1 \mathrm{ng} \mathrm{ml}{ }^{-1}\right)$. After $6 \mathrm{~h}$, the number of cells per square millimetre that passed through the transwell was measured. Data are means \pm s.e.m. $(n=3)$. (c) Osteoblasts in osteogenesis induction medium (OIM) were treated once with IL-1 $\beta$ ( $1 \mathrm{ng} \mathrm{ml}^{-1}$ during 4 days). (d) After 28 days, matrix mineralization was revealed with alizarin red staining. Representative wells are shown. For a-c, data are means \pm s.e.m. $(n \geq 3) .{ }^{\star} P<0.05,{ }^{\star \star} P<0.01$; Student's $t$-test.

Fig. 12). The inhibitory effects of IL-1 $\beta$ and their magnitudes were very similar to the ones observed with bone-derived MSCs. Therefore, we chose to use bone-derived MSCs for all the subsequent experiments involving MSCs. Lastly, we tested the effects of IL-1R1/MyD88 signalling on osteoblasts. IL-1 $\beta$ inhibited osteoblast proliferation, migration and differentiation (Fig. 4). However, the effects of the cytokine were less strong on osteoblasts compared with MSCs, suggesting that the inhibitory effects of IL-1R1/MyD88 signalling are more severe on progenitor cells.

Then, we examined whether proliferation and osteoblastic differentiation of MSCs are also inhibited by IL-1R1/MyD88 signalling in vivo. As a model, carboxyfluorescein succinimidyl ester (CSFE)-labelled MSCs from Illr1 ${ }^{-1-}, M_{y d 88^{-/-}}$, or wt mice were delivered into calvarial defects with a fibrin matrix and the labelled cells were recovered 7 days later using fluorescence-

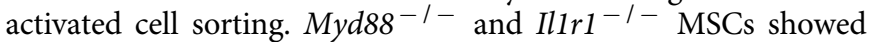
significantly less florescence (Fig. 5a,b; Supplementary Fig. 13), indicating that they proliferated more than wt MSCs. In addition, expression of osteoblast differentiation markers (alkaline phosphates, runt-related transcription factor 2 and integrin-binding sialoprotein) was significantly higher in $M y d 88^{-/-}$and $I l 1 r 1^{-/-}$ MSCs compared with wt MSCs (Fig. 5c), demonstrating that differentiation of transplanted MSCs towards osteoblasts is impaired by IL-1R1/MyD88 signalling. In addition, we examined if mobilization of stem/progenitor cells following tissue injury is also affected by IL-1R1/MyD88 signalling. As a model, calvarial defects in $I l 1 r 1^{-1-}, M y d 88^{-1-}$ or wt mice were treated with a fibrin matrix containing PDGF-BB-a very potent recruiting factor for stem/progenitor cells ${ }^{35}$. After 7 days, the cells recruited in the remodelled fibrin matrix were analysed by flow cytometry. The percentage of MSC-like cells expressing typical surface markers of MSCs $\left(\mathrm{CD}_{4} 5^{-}, \mathrm{CD} 90^{+}, \mathrm{CD} 44^{+}, \mathrm{Sca}-1^{+}\right.$and $\mathrm{CD}^{2} 9^{+}$) was twice higher in $\operatorname{Illr} 1^{-/-}$and $M y d 88^{-/-}$mice compared with wt mice (Fig. 5d; Supplementary Fig. 14).

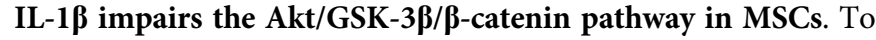
gain insights on the molecular mechanism by which IL-1R1/ MyD88 signalling inhibits MSC proliferation and migration, we used an antibody array to analyse the phosphorylation state of key intercellular signalling molecules following co-stimulation with IL-1 $\beta$ and PDGF-BB (Supplementary Fig. 15). Among the proteins tested, the strongest phosphorylation signal induced by PDGF-BB was for the serine/threonine kinase Akt. In contrast, Akt phosphorylation at $\mathrm{Thr}^{308}$ and $\mathrm{Ser}^{473}$ considerably decreased over time, when cells were co-stimulated with IL-1 $\beta$ (Fig. 6a), indicating that $\mathrm{IL}-1 \mathrm{R} 1 / \mathrm{MyD} 88$ signalling inhibits the Akt pathway. Then, since Wnt/ $\beta$-catenin signalling is critical for the differentiation of MSCs into osteoblasts ${ }^{36,37}$, we investigated if IL-1R1/MyD88 signalling disturbs this pathway, by analysing the phosphorylation state of $\beta$-catenin following stimulation with IL-1 $\beta$. IL-1 $\beta$ induced $\beta$-catenin phosphorylation, indicating that $\beta$-catenin was undergoing degradation. Confirming $\beta$-catenin degradation, the total concentration of $\beta$-catenin decreased gradually over time (Fig. 6b). In addition, we examined whether $\beta$-catenin degradation induced by IL-1R1/MyD88 signalling is linked to a decrease of Akt activity. We focused on GSK-3 $\beta$, which is a kinase within the $\beta$-catenin destruction complex, because Akt inactivates GSK-3 $\beta$ by phosphorylation of $\mathrm{Ser}^{9}$ (ref. 38). In MSCs that were stimulated with IL-1 $\beta$, the concentration of phosphorylated GSK-3 $\beta$ gradually decreased over time (Fig. $6 \mathrm{c}$ ), indicating that IL-1R1/MyD88 signalling inhibits the Akt/GSK-3 $\beta / \beta$-catenin singling pathway.

To verify that Akt activity and $\beta$-catenin directly contribute to MSC proliferation, migration, differentiation and MSC-driven bone regeneration, we used specific inhibitors for Akt and $\beta$-catenin, respectively, MK-2206 and XAV-939. MK-2206 directly inhibits Akt phosphorylation at $\mathrm{Ser}^{473}$ and $\mathrm{Thr}^{308}$, while XAV-939 promotes $\beta$-catenin degradation through stabilization of $\operatorname{axin}^{39}$. Firstly, both inhibitors were confirmed to be effective in MSCs (Supplementary Fig. 16). Then, we found that Akt 
a

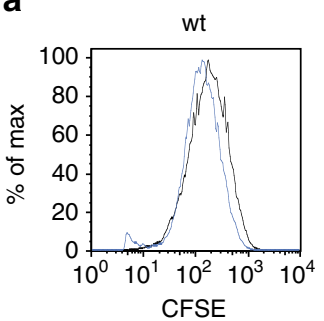

c
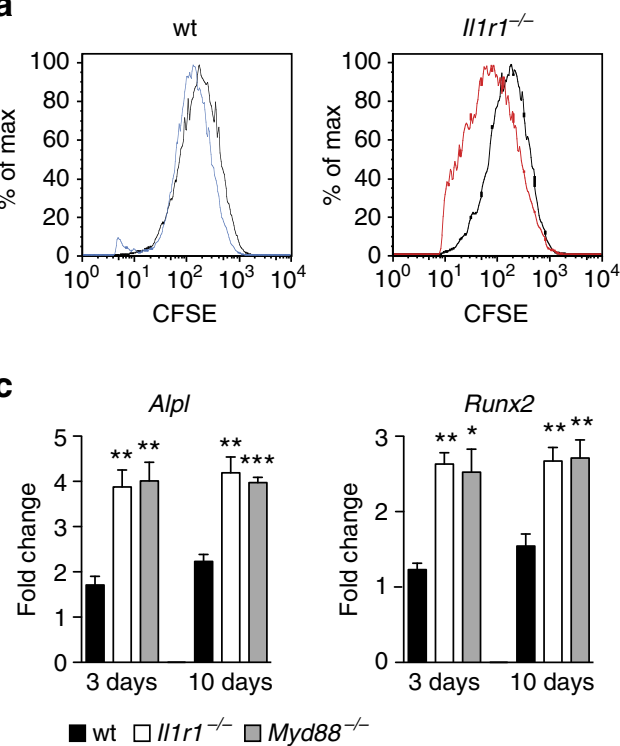
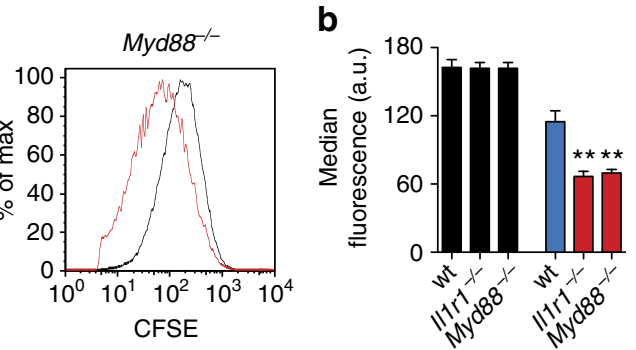

d

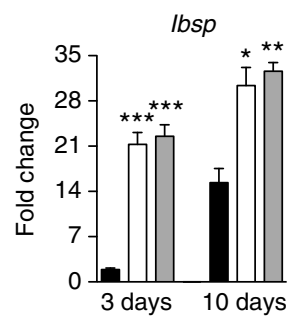

Figure 5 | Transplanted MSC functions and mobilization of MSC-like cells are inhibited by IL-1R1/MyD88 signalling. (a-c) Carboxyfluorescein

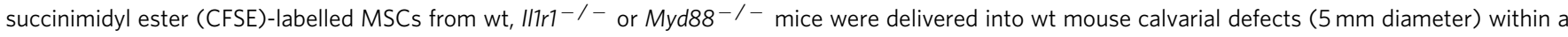
fibrin matrix. After 7 days, partially remodelled fibrin matrices were removed from the defect and digested to recover cells. (a) Difference in proliferation between $\mathrm{wt}, 111 \mathrm{r} 1^{-/-}$and $\mathrm{Myd} 88^{-/-}$MSCs was determined by comparing their fluorescence intensity using flow cytometry. MSC proliferation is inversely proportional to the fluorescence intensity. Representative histogram plots are shown. Black curves represent cells cultured in vitro with $1 \%$ serum (no proliferation control). (b) Median fluorescence of MSCs 7 days after implantation. Data are means \pm s.e.m. $(n=3)$. ${ }^{\star \star} P<0.01$; Student's $t$-test. (c) CFSE-labelled MSCs were sorted by fluorescence-activated cell sorting and further cultured in osteogenesis induction medium. Expression of osteoblast-specific genes was determined by quantitative PCR, after 3 and 10 days. Fold changes in gene expression relative to MSCs cultured in normal medium are shown. Alpl, alkaline phosphatase; Runx2, runt-related transcription factor 2; lbsp, integrin-binding sialoprotein. (d) Calvarial defects in wt, $11171^{-/}$or $\mathrm{Myd} 88^{-/}$mice were treated with fibrin matrices containing PDGF-BB $(1 \mu \mathrm{g})$. After 7 days, fibrin matrices were recovered and digested to recover cells. Percentages of $\mathrm{MSC}$-like cells $\left(\mathrm{CD} 90^{+}, \mathrm{CD} 45^{-}, \mathrm{Sca}-1^{+}, \mathrm{CD} 44^{+}\right.$and $\mathrm{CD} 29^{+}$cells $)$recruited within the matrices were analyzed by flow cytometry. Data are means \pm s.e.m. $\left(n=6\right.$ per condition). ${ }^{\star} P<0.05,{ }^{\star \star} P<0.01,{ }^{\star \star \star} P<0.001$; Student's $t$-test.

inhibition by MK-2206 significantly inhibits proliferation, differentiation and migration of MSCs (Fig. 6d-f). Moreover, similarly to the effect IL-1 $\beta$, MK-2206 induced the dephosphorylation of GSK-3 $\beta$ (Fig. 6c). Promotion of $\beta$-catenin degradation by XAV-939 had no significant effect on MSC proliferation (Fig. 6d) and migration (Fig. 6e), but significantly reduced MSC differentiation into osteoblasts (Fig. 6f). Lastly, we verified that Akt and $\beta$-catenin pathways are important for bone regeneration stimulated by MSC delivery. As a model, we treated

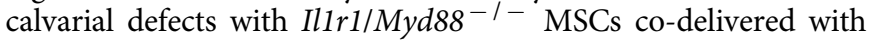
MK-2206 or XAV-939 and we analysed regeneration after 4 weeks. Since Il1r1/Myd88-I- MSCs are not responsive to IL-1, their Akt activity and $\beta$-catenin level were affected by the inhibitors, but not by IL-1 present in the defect microenvironment. The regeneration induced by $\operatorname{ll} 1 \mathrm{r} 1 / \mathrm{Myd} 88^{-/-}$ MSCs co-delivered with inhibitors was significantly lower

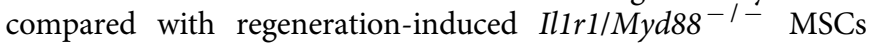
delivered alone (Fig. 6g,h), showing that both Akt and $\beta$-catenin pathways are critical for MSC-driven bone regeneration.

Inhibition of IL-1R1/MyD88 signalling promotes regeneration. Since we found that IL-1R1/MyD88 signalling represses the regenerative capacities of MSCs, we thought to inhibit this pathway to create a pro-regenerative niche supporting endogenous and transplanted stem cells. As a proof of concept, we engineered a cell delivery system based on fibrin matrix functionalization with IL-1R1/MyD88 signalling inhibitors. We chose two different strategies: (i) delivering the natural inhibitor of IL-1R1, IL-1Ra; (ii) delivering a MyD88 inhibitory peptide, RDVLPGTCVNS (MyD88-I) ${ }^{40}$, which inhibits MyD88 homodimerization. To deliver MyD88-I accurately, MyD88-I was engineered to be covalently crosslinked into fibrin matrix and to translocate into cells. A fibrin-binding sequence derived from $\alpha_{2}$-plasmin inhibitor ${ }^{41}\left(\alpha_{2}-\mathrm{PI}_{1-8}, \mathrm{NQEQVSPL}\right)$ was added at the $\mathrm{N}$ terminus of the peptide, followed by a plasmin/matrix metalloproteinase-sensitive sequence ${ }^{42}$ (VPMSMRGG) and a membrane translocation sequence derived from antennapedia/ homeobox protein ${ }^{43}$ (RQIKIWFQNRRMKWKK). Therefore, the peptide is covalently crosslinked into fibrin, during the natural polymerization process of the matrix ${ }^{41}$. Then, following matrix remodelling, the peptide is released by proteases, translocates into cells and ultimately inhibits IL-1R1 signalling (Fig. 7a). First, we confirmed that the engineered peptide could inhibit IL-1R1/ MyD88 signalling, as shown by its ability to significantly impair the release of cytokines from MSCs following stimulation with IL-1 $\beta$ (Supplementary Fig. 17). Next, we used the critical calvarial defect model again for testing the cell delivery system, since this versatile model allows for evaluation of biomaterials and bone tissue engineering approaches within a reproducible orthotopic site $^{25,44}$. Bone defect were treated with or without MSCs codelivered with IL-1Ra $(1 \mu \mathrm{g})$ or $\alpha_{2} \mathrm{PI}_{1-8}-\mathrm{MyD} 88-\mathrm{I}(4 \mu \mathrm{g})$. Analysis of bone regeneration after 2 month revealed that delivering IL-1Ra or $\alpha_{2} \mathrm{PI}_{1-8}-\mathrm{MyD} 88$-I alone improves bone regeneration compared with treatment with fibrin only (Fig. 7b,c). Strikingly, treatment with MSCs co-delivered with IL-1Ra or $\alpha_{2} \mathrm{PI}_{1-8^{-}}$ MyD88-I led to a marked increase of bone tissue deposition as to treatment with MSCs only, with no signs of bone overgrowth and yielding coverage at $78 \%$ and $93 \%$, respectively (Fig. $7 \mathrm{~b}, \mathrm{c}$ ).

\section{Discussion}

Tissue injury and the following healing process are almost always accompanied with an immune response. Therefore, 
a
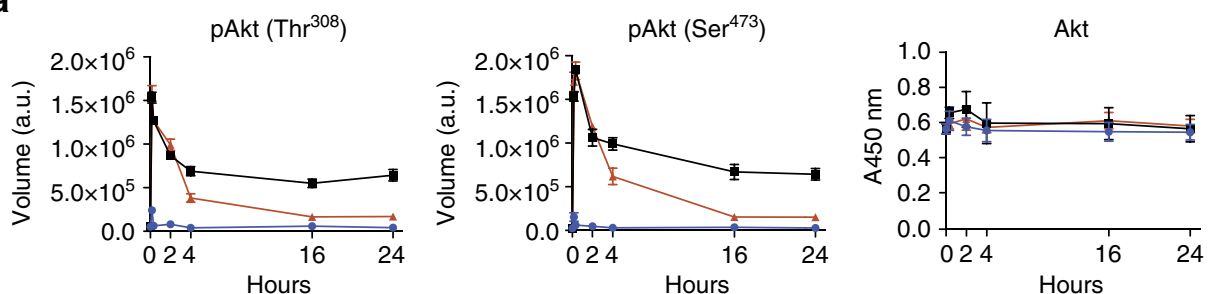

$\rightarrow$ PDGF-BB $\rightarrow$ IL-1 $\beta \rightarrow$ PDGF-BB+ IL-1 $\beta$

b

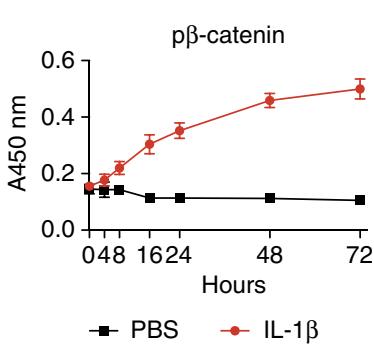

C

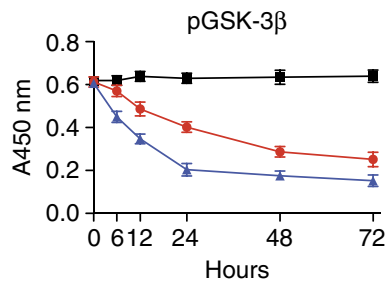

$\rightarrow$ PBS $\rightarrow$ IL-1 $\beta \quad$ × MK-2206
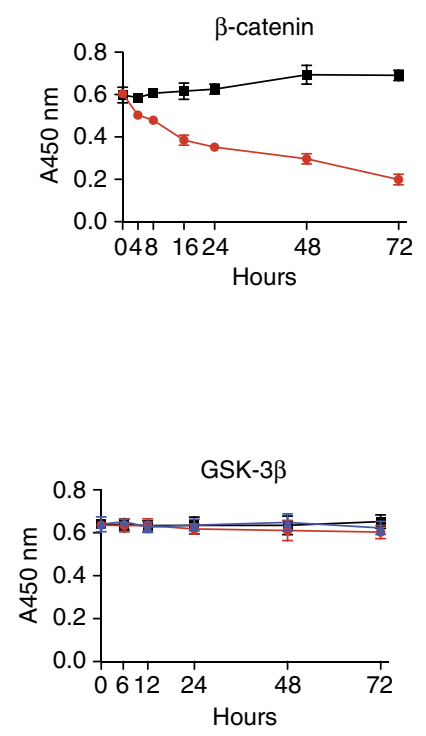

d

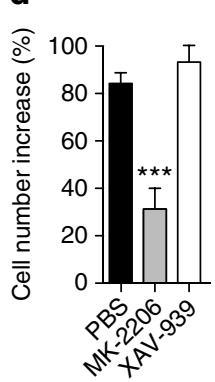

g

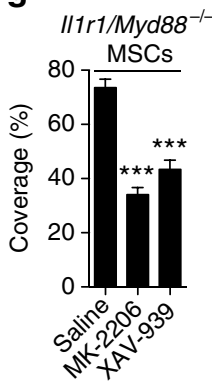

h
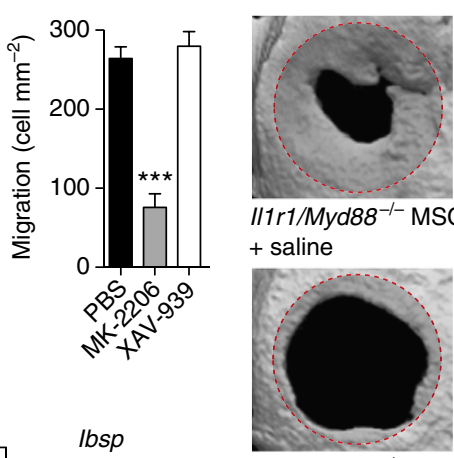

$1 / 1 \mathrm{r} 1 / \mathrm{Myd} 88^{-/-} \mathrm{MSCs}$

+ MK-2206

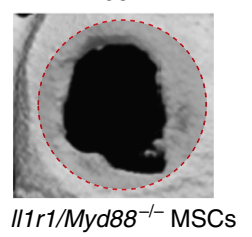

+ XAV-939

Figure 6 | IL-1R1/MyD88 signalling impairs MSC functions via inhibition of the Akt/GSK-3/ $/ \boldsymbol{\beta}$-catenin pathway. (a) MSCs were stimulated with PDGF-BB $\left(5 \mathrm{ng} \mathrm{ml}^{-1}\right), \mathrm{IL}-1 \beta\left(1 \mathrm{ng} \mathrm{ml}^{-1}\right)$ or both. Phosphorylation of Akt at $\mathrm{Thr}^{308}$ and $\mathrm{Ser}^{473}$ was quantified using an antibody array. Akt was measured by enzyme-linked immunosorbent assay. (b,c) MSCs were treated with IL-1 $\beta\left(1 \mathrm{ng} \mathrm{ml}{ }^{-1}\right.$ ). Phosphorylated $\beta$-catenin ( $p \beta$-catenin), total $\beta$-catenin,

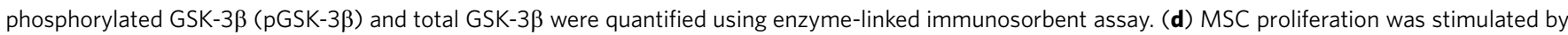
PDGF-BB $\left(5 \mathrm{ng} \mathrm{ml}^{-1}\right.$ ) with PBS, Akt inhibitor (MK-2206, $10 \mu \mathrm{M}$ ), or $\beta$-catenin inhibitor (XAV-939, $\left.10 \mu \mathrm{M}\right)$. After $72 \mathrm{~h}$, cell number increase was measured. (e) Migration of MSCs through a migration transwell was induced by PDGF-BB ( $5 \mathrm{ng} \mathrm{ml}^{-1}$ ) with PBS, MK-2206 (10 $\mu$ M), or XAV-939 (10 $\mu$ M). After $6 \mathrm{~h}$, the number of cells per square millimetre that passed through the transwell was counted. (f) MSCs in osteogenesis induction medium were treated with PBS, MK-2206 $(10 \mu \mathrm{M})$, or XAV-939 $(10 \mu \mathrm{M})$. After 7 and 14 days, expression of osteoblast-specific genes was determined by quantitative PCR. Fold changes in gene expression relative to MSCs cultured in normal medium are shown. Alpl, alkaline phosphatase; Runx2, runt-related transcription factor 2; Ibsp, integrin-binding sialoprotein. For a-f data are means \pm s.e.m. $(n \geq 3)$. ${ }^{\star \star} P<0.01,{ }^{\star \star \star} P<0.001$; Student's $t$-test. (g,h) Critical size calvarial defects ( $5 \mathrm{~mm}$ diameter) in mice were treated with $1 / 1 \mathrm{r} 1 / \mathrm{Myd} 88^{-/-}$MSCs co-delivered in fibrin matrix with saline, MK-2206 (1 mM), or XAV-939 (1 mM). Four weeks after treatment, bone regeneration was measured by microCT as coverage of the defect. Data are means \pm s.e.m. ( $n=6$ per condition). ANOVA with Bonferroni post hoc test for pair-wise comparisons; ${ }^{* \star \star} P<0.001$. Representative calvarial reconstructions are shown in $\mathbf{h}$. Original defect area is shaded with a red dotted outline. ANOVA, analysis of variance.

understanding the immune regulations of tissue repair and regeneration could be fundamental for designing effective regenerative therapies ${ }^{1,2}$. Particularly, the regenerative capacities of endogenous and transplanted stem cells could rely on the inflammatory/immune microenvironment at the injury site $1,2,23,45,46$. For example, it has been shown that recipient $\mathrm{T}$ cells negatively regulate bone formation by autologous MSCs, in the mouse ${ }^{45}$. Moreover, MSC-mediated bone regeneration in 


\section{a}

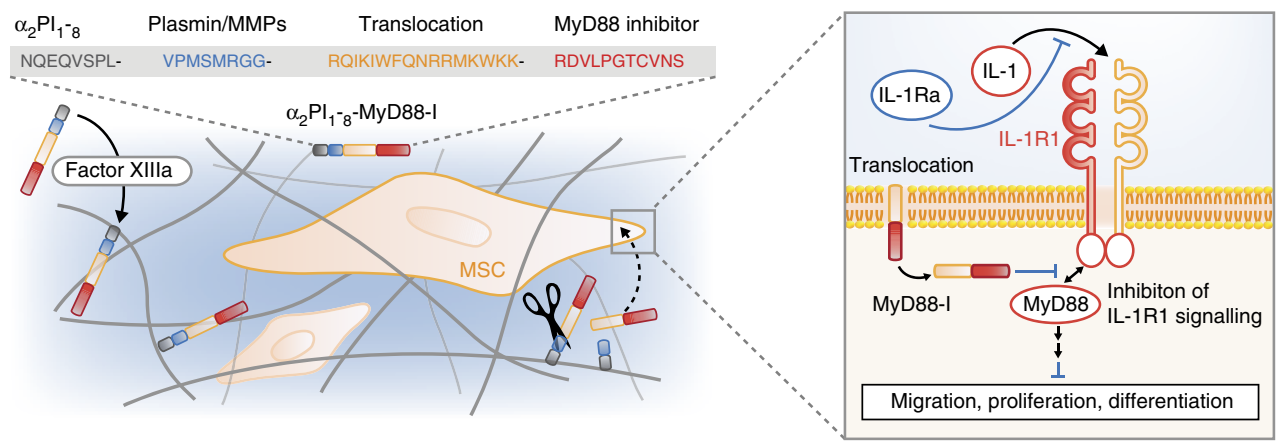

b C

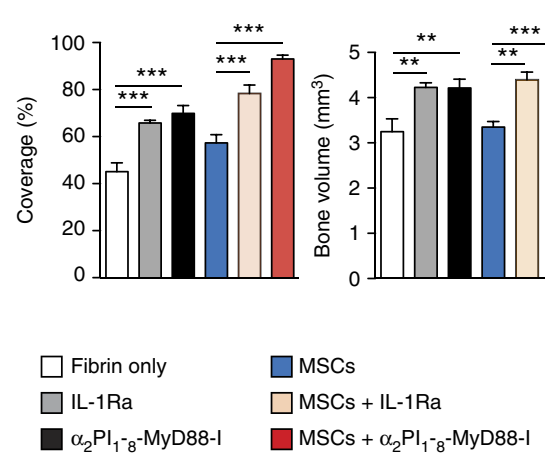

C Fibrin only

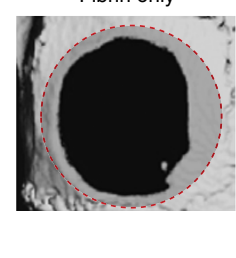

MSCs

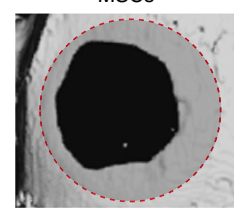

IL-1Ra

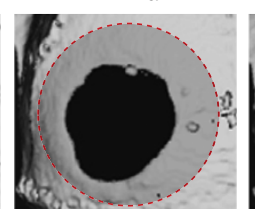

MSCs +

IL-1Ra

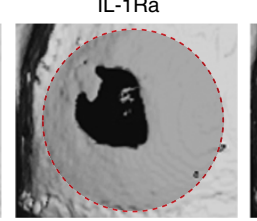

$\alpha_{2} \mathrm{PI}_{1}-8-\mathrm{MyD} 88-\mathrm{I}$

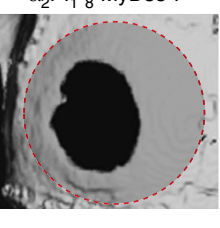

$\mathrm{MSCs}+$ $\alpha_{2} \mathrm{PI}_{1}-8^{-M y D 88-\mathrm{I}}$

Figure 7 | Inhibition of IL-1R1/MyD88 signalling promotes MSC-driven bone regeneration. (a) Design of the MyD88 inhibitor peptide $\left(\alpha_{2} \mathrm{PI}_{1-8}-\mathrm{MyD} 88-1\right)$. A fibrin-binding sequence derived from $\alpha_{2}-\mathrm{PI}_{1-8}$ (NQEQVSPL, in grey) is followed by a plasmin/matrix metalloproteinase-sensitive sequence (VPMSMRGG, in blue), a membrane translocation sequence (RQIKIWFQNRRMKWKK, in orange) and the MyD88 inhibitor peptide (RDVLPGTCVNS, in red). The peptide is covalently crosslinked into fibrin fibres (in grey) during the natural polymerization process of the matrix via the transglutaminase activity of factor XIIIa. Then, following matrix remodeling, the peptide is released by proteases (represented as scissors), translocates into cells, and ultimately inhibits IL-1R1/MyD88 signalling. (b,c) Critical size calvarial defects ( $5 \mathrm{~mm}$ diameter) in mice were treated with or without MSCs delivered by a fibrin matrix. Fibrin matrices were functionalized with IL-1Ra $(1 \mu \mathrm{g})$ or $\alpha_{2} \mathrm{Pl}_{1-8}-\mathrm{MyD} 88-\mathrm{I}(4 \mu \mathrm{g})$. Eight weeks after treatment, bone regeneration was measured by microCT as coverage of the defect and bone volume. Data are means \pm s.e.m. ( $n=6$ per condition). ANOVA with Bonferroni post hoc test for pair-wise comparisons; ${ }^{\star \star} P<0.01,{ }^{\star \star \star} P<0.001$. Representative calvarial reconstructions are shown in $\mathbf{c}$.

Original defect area is shaded with a red dotted outline. ANOVA, analysis of variance.

the rat has been enhanced, by inhibiting of NF- $\kappa \mathrm{B}$, which is a major transcription factor regulating both the innate and adaptive immune response. As another example, we recently found that self-RNA released after radiation-induced injury promote crypt stem cells death through TLR3 signalling ${ }^{23}$. Since tissue injury and the healing response usually lead to the release of endogenous danger signals such as TLR and IL-1R1 ligands ${ }^{10,11}$, and because TLRs and IL-1R1 have been shown to influence the repair of several tissues ${ }^{13-23,47}$, our initial motivation was to determine the impact of TLR/IL-1R1 signalling during bone regeneration.

While some TLRs have been shown to have a role in the repair of certain organs including brain ${ }^{16,19,20}$, heart ${ }^{13,47}$, liver ${ }^{14}$, kidney $^{15}$ and skin $^{22}$, all TLR knockout mice that we tested displayed normal bone regeneration in specific pathogen-free conditions. In contrast, MyD88- and IL-1R1-deficient mice exhibited better bone regeneration, indicating that IL-1R1/ MyD88 signalling negatively regulates bone regeneration. Since IL-1R1/MyD88 signalling is well known to modulate the activity of immune cells, we first suspected that this signalling was inhibiting bone regeneration by acting on the immune cells mobilized after injury. However, using the chimeric mouse model where bone marrow-derived immune cells and osteoclasts are deficient for MyD88, we found that IL-1R1/MyD88 signalling inhibits bone regeneration by acting on tissue-resident cells except osteoclasts. An ideal way to determine if IL-1R1/MyD88 signalling negatively regulated the regenerative capacity of MSCs in vivo would have been to analyse bone regeneration in a mouse having only these cells deficient for IL-1R1 or MyD88. Unfortunately, due to the lack of very specific markers for MSCs, there are currently no accurate methods to create such conditional knockout mouse. Therefore, as a model to explore whether IL-1R1/MyD88 signalling inhibits MSC-driven bone regeneration, we compared bone healing stimulated by the local delivery of bone-derived MSCs from wt, Illr1 ${ }^{-1-}$ or $M y d 88^{-1-}$. We found that a much better regeneration is induced by $I l 1 r 1^{-1-}$ or Myd88-1- MSCs, indicating that IL-1R1/MyD88 signalling inhibits bone regeneration induced by MSCs.

Among IL-1R1 ligands ${ }^{26}$ (IL-1 $\alpha$, IL-1 $\beta$ and IL-1Ra), we observed that IL-1 $\beta$ and IL-1Ra are present at relatively high concentration in the defect during the first 10 days following calvarial injury, while the concentration of IL-1Ra drastically increases afterward. This observation suggests that the IL-1R1/MyD88 signalling inhibiting bone regeneration in this model occurs for at least 1 week post injury. Interestingly, the concentration of IL-1 $\beta$ was about twice lower in calvarial defects of mice having a much lower number monocytes/macrophages, showing that these immune cells significantly contribute to the presence of IL-1 $\beta$. Nevertheless, other cell types such as recruited neutrophils, mesenchymal cells and endothelial cells probably 
contribute to the presence of IL-1 $\beta$ in the defect microenvironment. In addition, in the case of transplanted MSCs, the stem cells could also release IL-1 $\beta$. Importantly, we found that IL-1 $\beta$ significantly impairs colony formation of freshly isolated (primary) MSCs, as well as their differentiation towards osteoblasts. Although MSCs phenotype and proprieties can change during in vitro expansion, a strong inhibitory effect of IL-1 $\beta$ was also observed in cultured (expended) MSCs, indicating that IL-1 $\beta$ affects both primary and in vitro-expanded MSCs. Notably, while primary bone-derived MSCs and primary bone marrow-derived MSCs were reported to differ in stem cells antigen-1 and nestin expression, c.f.u.-F and osteoblastic differentiation potential ${ }^{48,49}$, the inhibitory effects of IL-1R1/ MyD88 signalling on bone-derived MSC and bone marrowderived MSC were the same. IL-1 $\beta$ also inhibited proliferation, migration and differentiation of osteoblasts, but the inhibitory effects of IL-1 $\beta$ on osteoblasts were less strong, compared with MSCs, suggesting that IL-1R1/MyD88 signalling most likely inhibits bone regeneration by acting principally on stem/progenitor cells. Tracing the fate of transplanted wt,

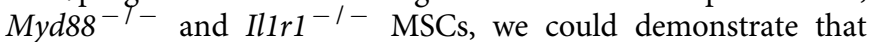
both proliferation and osteoblastic differentiation of MSCs delivered in bone defect are impaired by IL-1R1/MyD88 signalling. Moreover, when we examined the mobilization of stem/progenitor cells following bone injury, $M y d 88^{-/-}$and Ill $r 1^{-/}$mice-having no cells responsive to IL-1 $\beta$ - mobilized a higher percentage of cells having typical MSC markers. The cell population detected within the defects most likely contained MSCs, while other cell types that also express MSC markers such as pericytes ${ }^{50}$ could have been detected. Still, IL-1R1/MyD88 signalling probably inhibits the mobilization of MSCs in the defect, since IL-1 $\beta$ strongly inhibits MSC migration in vitro, and

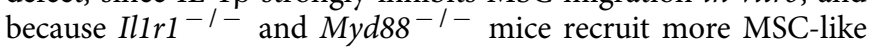
cells after bone injury.

Exploring the signalling mechanism by which IL-1 $\beta$ inhibits MSC regenerative functions, we first found that IL-1 $\beta$ promotes the dephosphorylation of Akt. Therefore, since Akt is a central node in cell signalling downstream many growth factor receptors such as PDGF and fibroblast growth factor receptors ${ }^{38}$, IL-1R1/MyD88 signalling probably attenuates MSC response to most Akt-dependent growth factors. Secondly, we found that IL-1 $\beta$ induces $\beta$-catenin phosphorylation and degradation, suggesting that IL-1R1/MyD88 directly impairs canonical Wnt signalling, which is critical for MSC differentiation into osteoblasts $^{36,37}$. Interestingly, these findings are in line with another study demonstrating that NF- $\mathrm{KB}$ - which is activated by IL-1R1 signalling ${ }^{26}$ - promotes $\beta$-catenin degradation in MSCs and impairs their differentiation into osteoblasts ${ }^{51}$. Moreover, we found that $\beta$-catenin degradation induced by IL- $1 \beta$ is linked to an increase of active GSK-3 $\beta$ (unphosphorylated) via a decrease of active Akt (unphosphorylated). Taken together, our data show that IL-1R1/MyD88 signalling inhibits the Akt/GSK-3 $\beta / \beta$-catenin singling pathway in MSCs. Yet, the detailed molecular mechanism by which this signalling pathway is inhibited still needs to be determined. For instance, IL-1 $\beta$ could stimulate the expression of phosphatases specific for Akt or induce the expression of proteins involved in $\beta$-catenin degradation. Interestingly, it has been shown that NF- $\kappa \mathrm{B}$ activation in MSCs promotes $\beta$-catenin ubiquitination and degradation through induction of E3 ubiquitin-protein ligase Smurf1 and Smurf2 (ref. 51), giving some insights about possible mechanisms. We could also show that the Akt and $\beta$-catenin pathways directly contribute to MSC proliferation, migration and differentiation, using potent and selective inhibitors for these molecules. As expected, Akt activity was critical for MSC migration, proliferation and differentiation, since these processes are known to be dependent on $\mathrm{Akt}^{38,52}$. On the other hand, $\beta$-catenin is probably weakly involved in MSC proliferation and migration, since $\beta$-catenin inhibition principally affected MSC differentiation into osteoblasts. Nevertheless, Akt and $\beta$-catenin pathways have been shown to positively regulate bone healing ${ }^{52,53}$. By co-delivering the inhibitors in vivo, we were also able to observe that both pathways are essential for bone regeneration induced by MSC delivery.

After having revealed that IL-1R1/MyD88 signalling inhibits the regenerative potentials of MSCs, we engineered a proof of concept MSC delivery system based on fibrin matrix functionalization with IL-1R1/MyD88 signalling inhibitors. As a first inhibitor, we chose IL-1Ra, since the protein is the natural antagonist of IL-1R1. Moreover, just as fibrin, IL-Ra is clinically relevant, since the molecule is clinically available for the treatment of rheumatoid arthritis. As a second inhibitor, we chose to deliver $\alpha_{2} \mathrm{PI}_{1-8}-\mathrm{MyD} 88-\mathrm{I}$, because synthetic peptide delivery could be more cost effective than recombinant protein delivery. Strikingly, we found that delivering MSCs with IL-1Ra or $\alpha_{2} \mathrm{PI}_{1-8}-\mathrm{MyD} 88-\mathrm{I}$ led to a large increase of bone tissue deposition as to treatment with MSCs only. Interestingly, $\alpha_{2}-\mathrm{PI}_{1-8}-\mathrm{MyD} 88-\mathrm{I}$ was slightly more efficient than IL-1Ra, yielding coverage near to $100 \%$. This difference could be explained by the higher concentration of the peptide used compared with IL-1Ra $(20$ versus $2 \mu \mathrm{M})$ and because $\alpha_{2}-\mathrm{PI}_{1-8}-\mathrm{MyD} 88-\mathrm{I}$ was engineered to be released in a controllable manner following fibrin matrix remodelling. Yet, the delivery of a fibrin-binding version of IL-1Ra or the co-delivery of IL-1Ra with $\alpha_{2}-\mathrm{PI}_{1-8}-\mathrm{MyD} 88$-I at lower doses could be very effective. In addition, while the calvarial critical size defect is a well-accepted model that is usually considered as translationally relevant ${ }^{25,44}$ further tests will be required to predict the clinical potential of IL-1R1/MyD88 signalling inhibition. Experiments in more realistic models would also confirm the physiological relevance of the findings. Typically, these tests would be done using critical size bone defect models in larger animal closer to human such as dogs, goats or sheep, since success in rodents is not enough to open the door for human trials ${ }^{24,54}$.

Most importantly, we demonstrated that MSCs delivered without an inhibitor of IL-1R1/MyD88 signalling could not promote regeneration, reflecting that one cannot assume that stem/progenitor cells automatically stimulate tissue healing. In other words, applying stem cells to damaged tissue with little or no attempt to prepare and engineer the regenerative niche is unlikely to promote engraftment ${ }^{2}$. Indeed, several studies have shown that MSCs from different sources are inefficient in promoting bone regeneration ${ }^{45,51,55,56}$. Moreover, regenerative medicine therapies based on stem cells did not yet demonstrate real effectiveness in the clinic $4,57,58$. Our poor understanding of how transplanted cells are controlled by the host tissue is probably one the main reasons underlying this modest translation to the clinic. On the front line, understanding and controlling the immune microenvironment at the delivery site could be the key to improve the efficacy of stem cell-based therapies ${ }^{2}$. Here, we revealed that the innate immune response via IL-1R1/MyD88 signalling impairs bone regeneration and the regenerative capacity of MSCs. By using a simple stem cell delivery integrating an inhibitor of IL-1R1/MyD88 signalling, we could considerably improve MSC-driven bone regeneration. Furthermore, such a strategy may be adapted into cell delivery systems using other biomaterial matrices or for MSC-based regenerative strategies targeting other tissues. This work highlights the crucial role of the innate immune response in modulating the regenerative capacity of stem cells and the importance of integrating a control of the host immune microenvironment into regenerative strategies. 


\section{Methods}

Animals. All animals were kept under specific pathogen-free conditions. Wt C57BL/6 mice were purchased from SLC Japan. Myd88 ${ }^{-1-}$ (ref. 59), Trif ${ }^{-1-}$ (ref. 60), $T l r 1^{-1-}$ (ref. 61), $T l r 5^{-1-}$ (ref. 62), Tlr $7^{-1-}$ (ref. 63), Tlr2/4/9-1(refs 64-66) and Illr1 ${ }^{-1-}$ (ref. 59) mice were backcrossed onto a C57BL/6 background for more than eight generations. All animal experiments were performed with the approval of the Animal Research Committee of the Research Institute for Microbial Diseases (Osaka University).

Calvarial defect model. Mice used for surgery were 10-12 weeks old. Mice were anaesthetized with isoflurane. The top of their head was shaved and a longitudinal incision was performed to reveal the skull. Bone tissue was exposed by retracting the soft tissues. Using a drill, two craniotomy defects $(5 \mathrm{~mm}$ diameter) were created in the parietal bones of the skull on each side of the sagittal suture line. The defects were washed with saline and covered with a fibrin matrix polymerized atop the dura $\left(40 \mu \mathrm{l}\right.$ per defect, $10 \mathrm{mg} \mathrm{ml}^{-1}$ fibrinogen (Enzyme Research Laboratories), $2 \mathrm{U} \mathrm{ml}^{-1}$ of thrombin (Sigma-Aldrich), $5 \mathrm{mM} \mathrm{CaCl}_{2}, 25 \mu \mathrm{g} \mathrm{ml}^{-1}$ aprotinin (Roche), $2 \times 10^{6} \mathrm{MSCs}$ ). For Akt and $\beta$-catenin inhibition experiments, MK-2206 or XAV-939 were added to the MSC mix to have a final concentration of $1 \mathrm{mM}$ per fibrin matrix. Then, the soft tissue was closed with stitches. As a painkiller, mice received a subcutaneous injection of Tramdol $\left(100 \mathrm{mg} \mathrm{kg}^{-1}\right)$.

Microcomputed tomography. Skulls were scanned with a Scan-Xmate RB080SS110 system (Comscan Techno Co., Ltd) for screening and with a microCT 40 (Scanco Medical AG) operated at energy of $70 \mathrm{kVp}$ and intensity of $145 \mathrm{~ms}$ for detailed measurements. Scans were performed at high-resolution mode resulting in a nominal isotropic resolution of $30 \mu \mathrm{m}$. After reconstruction, a 3D Gaussian filter (sigma 1.2, support 1) was applied to all images. Bone was segmented from background using a global threshold of $22.4 \%$ of maximum grey value. Afterwards, cylindrical masks were placed manually at the defects. Bone volume within these masks was calculated using a standardized procedure developed for quantitative bone morphometry ${ }^{67}$. Coverage was calculated on a dorso-ventral projection of the cylindrical area ${ }^{68}$.

Chimeric mice. Bone marrow cells $\left(1 \times 10^{7}\right)$ from 5-week-old $M y D 88^{-/-}$mice or wt mice were intravenously injected into lethally irradiated 4-weeks-old recipient wt mice. Mice were placed on $10 \mathrm{mll}^{-1}$ neomycin sulfate for 2 weeks post radiation. After 6 weeks, most of bone marrow-derived immune cells and osteoclasts in bone tissue should lack MyD88 (ref. 69). Mice were used for cranial surgery 8 weeks after bone marrow transplantation as described for the calvarial defect model. After 4 weeks, skulls were analysed by microCT and bone marrow from femurs was harvested to confirm the absence of MyD88 in chimeric mice. Bone marrow-derived cells were lysed with tissue protein extraction reagent (T-PER, Thermo Scientific) supplemented with protease inhibitor cocktail (one tablet of protease inhibitor cocktail (Roche) for $10 \mathrm{ml}$ ). The lysed cells were centrifuge at 5,000 g for $5 \mathrm{~min}$ and the supernatant was analysed using ELISA for MyD88 (MyBioSource).

Release of cytokines and inflammatory-associated molecules following bone injury. Calvarial defect ( $4 \mathrm{~mm}$ diameter) were treated with a fibrin matrix as described for the calvarial defect model. After 1, 3, 6, 10 and 15 days, the partially remodelled matrix and the bone tissue surrounding the defect $(1 \mathrm{~mm}$ farther) was collected. As a control a $5 \mathrm{~mm}$ diameter calvarial bone tissue was collected (day 0 ). Fibrinous matrices and tissue samples were incubated in $1 \mathrm{ml}$ of tissue protein extraction reagent (T-PER, Thermo Scientific) containing protease inhibitors (one tablet of protease inhibitor cocktail (Roche) for $10 \mathrm{ml}$ ) and homogenized with a tissue homogenizer. Tissue lysates were incubated $1 \mathrm{~h}$ at $37^{\circ} \mathrm{C}$ and centrifuged at $5,000 \mathrm{~g}$ for $5 \mathrm{~min}$. Supernatants were stored at $-80^{\circ} \mathrm{C}$. Cytokines were detected using an antibody array (Mouse Cytokine Array Panel A, R\&D Systems) and by ELISA (Mouse IL-1 beta/IL-1F2 DuoSet and Mouse IL-1ra/IL-1F3 DuoSet, R\&D Systems) according to the manufacturer's instructions. For the antibody array, $400 \mu \mathrm{l}$ of lysate was used. The chemiluminescent signals were detected using ImageQuant LAS 4000 and quantified with ImageQuant TL software (GE Healthcare Life Sciences). A measured volume over $1 \times 10^{6}$ was considered as a positive signal.

Monocytes/macrophages depletion. One day before surgery, $200 \mu \mathrm{l}$ of clodronate liposomes or empty liposomes (Anionic liposomes, FormuMAx Scientific Inc.) was intravenously injected in wt mice. Additional $50 \mu \mathrm{l}$ of clodronate liposomes or empty liposomes was intravenously injected right before surgery and every 2 days until day 6 . The concentration of IL- $1 \beta$ into the defect was measured by enzyme-linked immunosorbent assay (ELISA) as described above. The efficiency of monocytes/macrophages depletion was checked by measuring the percentage of $\mathrm{CD}_{11 \mathrm{~b}}{ }^{+}$cells in the spleen by flow cytometry (anti-mouse CD11b, Biolegends).

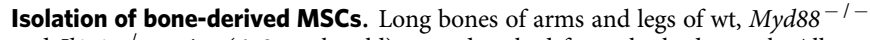
and $I l l r^{-1-}$ mice (6-8 weeks old) were detached from the body trunk. All muscles and cartilages were removed. The bones were rinsed with PBS and cut into three pieces, to have one diaphysis part and two metaphyses/epiphyses parts. The bone marrow within the medullary cavity of the diaphyses was flushed out using a 27 -Gauge needle attached to a $10 \mathrm{ml}$ syringe filled with $\alpha$-MEM containing $1 \%$ fetal bovine serum (FBS). Bones pieces, including diaphyses and metaphyses/epiphyses were washed with PBS and cut into $1-3 \mathrm{~mm}^{3}$ pieces. Bone chips were transferred in a $25 \mathrm{~cm}^{2}$ cell culture-treated flask with $3 \mathrm{ml}$ of $\alpha$-MEM medium containing $2 \mathrm{mM}$ L-glutamine, $100 \mathrm{mg} \mathrm{ml}^{-1}$ penicillin/streptomycin, $10 \% \mathrm{FBS}$, and $1 \mathrm{mg} \mathrm{ml}^{-1}$ collagenase type II (Life Technologies). Bone chips were digested for $1 \mathrm{~h}$ at $37^{\circ} \mathrm{C}$ to release most of hematopoietic cells on the inner interface of the bones. Then, the bone chips were washed with MSC culture medium ( $\alpha$-MEM, $2 \mathrm{mM}$ L-glutamine, $100 \mathrm{mg} \mathrm{ml}^{-1}$ penicillin/streptomycin, $10 \%$ heat inactivated MSC-certified FBS (Gibco)) and incubated at $37^{\circ} \mathrm{C}$ with $5 \% \mathrm{CO}_{2}$ in $6 \mathrm{ml}$ of MSC culture medium. Bone chips were kept in culture for 6 days with one medium change at day 3 . Then, the MSCs that have migrated out of the bone chips and formed colonies were detached using trypsin/EDTA. Cells were splitted at a ratio of 1:3 (passage 0 ) and the bone chips were reseeded together for allowing MSCs to continue migrating out for 3 more days. Five independent isolates were pulled together and MSCs were further expended for three passages before storage. The expression of MSC-specific surface marker was verified using flow cytometry. MSCs were stained for $15 \mathrm{~min}$ in $100 \mu \mathrm{l}$ of flow cytometry buffer (PBS containing 2\% of heat inactivated serum) containing anti-mouse antibodies (Biolegends): CD11, CD14, CD19, CD34, CD45.2, Ly-6 A/E (Sca-1), CD29, CD44, CD75 and CD90.1. Cells were washed twice with flow cytometry buffer and further analysed by flow cytometry (BD FACSCanto II). For cells used in colonies formation assay, bone pieces were gently disrupted using a mortar and pestle, in washing buffer (PBS with 2\% FBS and $1 \mathrm{mM}$ EDTA). Disrupted bone was rinsed with PBS containing $2 \%$ FBS and $1 \mathrm{mM}$ EDTA until bone fragments turned white. Then, bone fragments were transferred to a $100 \mathrm{~mm}$ dish containing a collagenase solution $(2 \mathrm{ml}$ of $0.25 \%$ collagenase Type I (Stemcell Technologies) in PBS containing 20\% FBS). Using a scalpel, bone fragments were cut into small pieces $(1-2 \mathrm{~mm})$ and transferred into a $50 \mathrm{ml}$ polypropylene tube with $10 \mathrm{ml}$ collagenase solution. Bone fragments were digested at $37^{\circ} \mathrm{C}$ under agitation for $45 \mathrm{~min}$. Then, $30 \mathrm{ml}$ of washing buffered was added and supernatant was filtered through a $70 \mu \mathrm{m}$ cell strainer. Cells were centrifuged at $300 \mathrm{~g}$ for $10 \mathrm{~min}$ and resuspend in $500 \mu \mathrm{l}$ of medium. Lastly, CD $45^{+}$cells were depleted (MagCellect Mouse Mesenchymal Stem Cell Isolation Kit, R\&D Systems) before colonies formation assays.

MSC isolation from bone marrow. Long bones of arms and legs of wt (6-8 weeks old) were detached from the body trunk. All muscles and cartilages were removed and the bones were rinsed with PBS. The bone marrow was flushed out using a 27 -Gauge needle attached to a $10 \mathrm{ml}$ syringe filled with $\alpha$-MEM containing $1 \%$ FBS Bone marrow cells were passed through a $70 \mu \mathrm{m}$ filter mesh and transferred in tissue culture-treated plate at a density of $2.5 \times 10^{7}$ cells per ml ${ }^{-1}$. Cells were incubated at $37^{\circ} \mathrm{C}$ with $5 \% \mathrm{CO}_{2}$ in a humidified chamber for $4 \mathrm{~h}$. Non-adherent cells were removed by changing the medium to culture medium ( $\alpha$-MEM containing $2 \mathrm{mM}$ of L-glutamine, $100 \mathrm{mg} \mathrm{ml}^{-1}$ penicillin/streptomycin, and $10 \% \mathrm{FBS}$ ). Thereafter, medium was replaced every $8 \mathrm{~h}$. After $72 \mathrm{~h}$, cells were washed with PBS and new medium was added. Then, medium changed every 3-4 days. After 2-3 weeks, MSC colonies formed were detached using trypsin/EDTA (passage 0). MSCs were expanded until 3 passages. For cells used in colonies formation assay, CD $45^{+}$ cells were depleted (MagCellect Mouse Mesenchymal Stem Cell Isolation Kit, R\&D Systems).

Colony formation assay. Primary cells were seeded in six-well plates (50 bone-derived cells) or 12-well plates (200 bone marrow-derived cells) and cultured in medium ( $\alpha$-MEM, $100 \mathrm{mg} \mathrm{ml}^{-1}$ penicillin/streptomycin, 20\% FBS) with or without $1 \mathrm{ng} \mathrm{ml}^{-1}$ of IL-1 $\beta$ for 12 days. Medium was changed once after 6 days. Then, cells were washed with PBS and stained with an ice-cold crystal violet solution $(0.5 \%$ in methanol). The number of colony ( $>50$ cells) was counted and their size was measured using ImageJ software. For osteobalstic differentiation of colonies, primary cells (50 bone-derived cells) were seeded in 24-well plate with osteogenesis induction medium ( $\alpha$-MEM with $2 \mathrm{mM}$ of $\mathrm{L}$-glutamine, $10 \% \mathrm{FBS}$, $100 \mathrm{mg} \mathrm{ml}^{-1}$ penicillin/streptomycin, $50 \mu \mathrm{M}$ ascorbate-phosphate, $10 \mathrm{mM}$ $\beta$-glycerolphophate and $100 \mathrm{ng} \mathrm{ml}^{-1}$ of human BMP-2 (R\&D Systems)) with or without $1 \mathrm{ng} \mathrm{ml}^{-1}$ of IL-1 $\beta$. After 28 days, cells were fixed with ice-cold methano and calcified nodules were stained using a calcified nodule staining kit (AK-21; Primary Cell).

Osteoblast isolation. Calvariae from 3-day-old mice were isolated and further digested in $\alpha$-MEM containing enzymes ( $0.1 \%$ collagenase type II (Life Technologies), $0.2 \%$ dispase (Sigma-Aldrich)) at $37^{\circ} \mathrm{C}$ for $20 \mathrm{~min}$ in a shaking water bath to release calvarial cells. The supernatant containing released cells was transferred in a new tube, centrifuged at $300 \times \mathrm{g}$, and the pellet was resuspended in medium ( $\alpha$-MEM, $100 \mathrm{mg} \mathrm{ml}^{-1}$ penicillin/streptomycin, $\left.10 \% \mathrm{FBS}\right)$. The calvariae were digested three more times for a total of four digestions. Digestions 3 and 4 containing osteoblasts were pulled together and transferred in a tissue 
culture-treated plate at a density of $3 \times 10^{5} \mathrm{cells} \mathrm{ml}^{-1}$. Calvarial cells were then maintained in culture for 2 weeks in osteogenesis inducing medium $(\alpha-M E M$ with $2 \mathrm{mM}$ of L-glutamine, $10 \% \mathrm{FBS}, 100 \mathrm{mg} \mathrm{ml}^{-1}$ penicillin/streptomycin, $50 \mu \mathrm{M}$ ascorbate-phosphate, $10 \mathrm{mM} \beta$-glycerolphophate, $100 \mathrm{ng} \mathrm{ml}^{-1}$ of human BMP-2 (R\&D Systems)) and stored before use.

Cell proliferation assays. Proliferation assays were performed as described previously ${ }^{70}$. Briefly, cells were starved $24 \mathrm{~h}$ with $\alpha$-MEM containing $1 \%$ FBS. Then, cells were seeded in 96-well plate with $\alpha$-MEM containing murine PDGF-BB ( $5 \mathrm{ng} \mathrm{ml}^{-1}$, Peprotech) and $1 \%$ FBS, or $\alpha$-MEM containing $10 \%$ FBS. Directly after, murine IL-1 $\beta$ (Peprotech) was added at concentrations ranging from 1 to $1,000 \mathrm{ng} \mathrm{ml}^{-1}$. For Akt and $\beta$-catenin inhibition experiments, MK-2206 (AdooQ Bioscience) or XAV-939 (AdooQ Bioscience) were added instead of IL-1 $\beta$ at a concentration of $10 \mu \mathrm{M}$. After $72 \mathrm{~h}$, cell number was quantified using PrestoBlue dye (Invitrogen). Percentage proliferation increases were calculated over basal proliferation (medium with $1 \%$ FBS and no PDGF-BB).

Migration assays. Migration assays were performed as described previously ${ }^{70}$. Briefly, solutions containing murine PDGF-BB $\left(5 \mathrm{ng} \mathrm{ml}^{-1}\right)$ with or without $1 \mathrm{ng} \mathrm{ml}^{-1}$ of murine IL-1 $\beta$ were added to the bottom side of a collagen type I (C4243, Sigma-Aldrich) coated transwell ( $8 \mu \mathrm{m}$ pore size, Millipore). For Akt and $\beta$-catenin inhibition experiments, MK-2206 or XAV-939 were added instead of IL- $1 \beta$ at a concentration of $10 \mu \mathrm{M}$. Directly thereafter, cells $(30,000$ cells per transwell) were added to the transwell upper chambers. After $6 \mathrm{~h}$, the numbers of cells that migrated to the bottom side of the membrane were counted. Membranes of each insert were removed and mounted on microscopy glass slides using Vectashield (Vector Laboratories) mounting medium containing DAPI. The number of cells that migrated to the bottom side of the membrane was counted.

Osteoblastic differentiation assays. Cells were seeded on 24-well plate at $70-80 \%$ confluency in osteogenesis inducing medium with or without murine $\mathrm{IL}-1 \beta\left(1 \mathrm{ng} \mathrm{ml}^{-1}\right)$. For Akt and $\beta$-catenin inhibition experiments, MK-2206 or XAV-939 were added instead of IL-1 $\beta$ at a concentration of $10 \mu \mathrm{M}$. After 4 days, osteogenesis inducing medium was replaced (without IL-1 $\beta$ ). Medium was changed every 3-4 days. Seven or 14 days following stimulation with IL-1 $\beta$, total RNAs were isolated, using RNeasy Plus Mini Kit (Qiagen) and reverse transcription was performed using ReverTra Ace (Toyobo Co., Ltd.). Quantitative PCR was performed with an ABI PRISM 7500 using TaqMan Assay with the following primers: Alpl Mouse, Mm00475834_m1; Runx2 Mouse, Mm00501580_m1; Ibsp Mouse, Mm00492555_m1; Eukaryotic 18S rRNA Endogenous Control (VIC/MGB Probe, primer limited) (Applied Biosystems). For extracellular matrix mineralization analysis, MSCs were cultured for 28 days in osteogenesis inducing medium. Then, cells were fixed with methanol and calcified nodules were stained using a calcified nodule staining kit.

Chondrogenic differentiation of MSCs. MSCs were transferred in a $15 \mathrm{ml}$ conical tubes (250,000 cells per tube), centrifuged at $200 \mathrm{~g}$ for $5 \mathrm{~min}$ and resuspended in D-MEM/F12. MSCs were centrifuged again and resupended in $0.5 \mathrm{ml}$ of $\mathrm{D}-\mathrm{MEM} / \mathrm{F} 12$ containing $100 \mathrm{mg} \mathrm{ml}^{-1}$ penicillin/streptomycin, $1 \%$ ITS supplement, $1 \times$ chondrogenic supplement (R\&D Systems), with or without murine IL-1 $\beta\left(1 \mathrm{ng} \mathrm{ml}^{-1}\right)$. Cells were centrifuged on more time at $200 \mathrm{~g}$ for $5 \mathrm{~min}$ to form a pellet. The cap of the tubes were loosen to allow gas exchange and the tubes were incubated upright at $37^{\circ} \mathrm{C}$ with $5 \% \mathrm{CO}_{2}$. The medium was replaced every 3 days (without IL-1 $\beta$ ). After 28 days, the spheroids were washed with PBS and fixed with $10 \%$ formalin for $60 \mathrm{~min}$. Spheroids were washed twice with water and stained with Alican Blue $8 \mathrm{GX}$ (Sigma-Aldrich, $0.1 \mathrm{mg} \mathrm{ml}^{-1}$ in ethanol/acetic acid solution (3:2)) overnight at room temperature in the dark. Spheroids were destained three times with an ethanol/acetic acid solution (3:2) and resuspended in PBS, before imaging.

Trophic factors secreted by MSCs. MSCs were seeded in six-well plates and cultured until $70-80 \%$ confluency. Cells were starved for $24 \mathrm{~h}$ with medium containing $1 \%$ FBS and further stimulated with PBS or IL-1 $\beta\left(1 \mathrm{ng} \mathrm{ml}^{-1}\right)$. After $24 \mathrm{~h}$ supernatants were collected and stored at $-80^{\circ} \mathrm{C}$. Trophic factors were detected using an antibody array focusing on angiogenic factors (Mouse Angiogenesis Antibody Array, R\&D Systems) according to the manufacturer's instructions, using $400 \mu \mathrm{l}$ of supernatant. The chemiluminescent signals were detected using ImageQuant LAS 4000 and quantified with ImageQuant TL software (GE Healthcare Life Sciences). A measured volume over $1 \times 10^{3}$ was considered as a positive signal.

Intracellular signalling array. MSCs were seeded in six-well plate and cultured until $60-70 \%$ confluency. Cells were starved $24 \mathrm{~h}$ with $\alpha$-MEM containing only $1 \%$ FBS. Then, cells were stimulated with murine PDGF-BB $\left(5 \mathrm{ng} \mathrm{ml}^{-1}\right)$, murine IL-1 $\beta$ $\left(1 \mathrm{ng} \mathrm{ml}^{-1}\right.$ ), or with both for $10 \mathrm{~min}$ to $24 \mathrm{~h}$. Phosphorylation and cleavage of intrecellular signalling molecules were detected using an antibody array (PathScan Intracellular Signalling Array, Cell Signalling) according to the manufacturer's instructions. The chemiluminescent signals were detected using ImageQuant LAS 4000 and quantified with ImageQuant TL software (GE Healthcare Life Sciences).

Akt signalling assay. MSCs were seeded in six-well plate and cultured until $60-70 \%$ confluency. Then, cells were stimulated with murine IL-1 $\beta\left(1 \mathrm{ng} \mathrm{ml}^{-1}\right)$ or PBS for 0 to $72 \mathrm{~h}$. For Akt and $\beta$-catenin inhibition experiments, MK-2206 or XAV-939 were added instead of IL-1 $\beta$ at concentrations ranging from 0 to $10 \mu \mathrm{M}$. Total Akt and phosphorylated Akt were quantified using ELISA (InstantOne ELISA, affimetrix eBioscience) according to the manufacturer's instructions.

Wnt/ $\beta$-catenin and GSK-3 $\beta$ signalling assays. MSCs were seeded in six-well plate and cultured until $60-70 \%$ confluency. Then, cells were stimulated with murine IL-1 $\beta\left(1 \mathrm{ng} \mathrm{ml}^{-1}\right)$ or PBS for 4 to $72 \mathrm{~h}$. For Akt and $\beta$-catenin inhibition experiments, MK-2206 or XAV-939 were added instead of IL-1 $\beta$ at a concentration ranging from 0 to $10 \mu \mathrm{M}$. Total $\beta$-catenin and phosphorylated $\beta$-catenin were quantified using ELISA (InstantOne ELISA, affimetrix eBioscience) according to the manufacturer's instructions. Total GSK- $3 \beta$ and phosphorylated GSK- $3 \beta$ were quantified using ELISA (InstantOne ELISA, affimetrix eBioscience) according to the manufacturer's instructions.

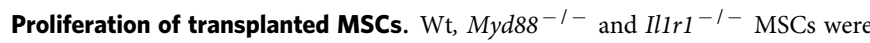
cultured until 80-90\% confluency. Cells were washed with PBS and incubated with $10 \mu \mathrm{M}$ of CSFE (Life Technologies) in PBS for $15 \mathrm{~min}$ at $37^{\circ} \mathrm{C}$. Thereafter, CSFE solution was removed and replaced with $\alpha$-MEM containing $10 \%$ FBS and further incubated for $30 \mathrm{~min}$ at $37^{\circ} \mathrm{C}$. Cells were detached using trypsin/EDTA and transplanted in cranial defect as described for the calvarial defect model $\left(2 \times 10^{6}\right.$ cells per defect within a $40 \mu \mathrm{l}$ fibrin matrix). As non-proliferating cells control, MSCs were seeded in cell culture plate with $\alpha$-MEM containing only $1 \%$ FBS. As a wt proliferating cells control MSCs were seeded in cell culture plate with $\alpha$-MEM containing $10 \%$ FBS or $10 \%$ FBS with $5 \mathrm{ng} \mathrm{ml}^{-1}$ of PDGF-BB. Medium was renewed after 4 days. Seven days after transplantation, the partially remodelled fibrinous matrices containing MSCs were removed from the defect and incubated in $1 \mathrm{ml}$ of an enzyme solution (trypsin $\left(10 \mathrm{mg} \mathrm{ml}^{-1}\right)$ and collagenase II $\left.\left(1 \mathrm{mg} \mathrm{ml}{ }^{-1}\right)\right)$ for $1 \mathrm{~h}$ at $37^{\circ} \mathrm{C}$. Then, the digested matrix was resuspended in $10 \mathrm{ml}$ of medium containing $10 \%$ serum, passed through a cell strainer and centrifuged. The cells were resuspended in $1 \mathrm{ml}$ of red blood cell lysis buffer (Sigma-Aldrich), incubated at room temperature for $5 \mathrm{~min}$, and resuspended in $10 \mathrm{ml}$ of flow cytometry buffer. For non-proliferating cells and wt proliferating cells controls, cells were detached from cell culture plate using trypsin/EDTA and resuspended in flow cytometry buffer. Cells were washed twice with flow cytometry buffer and further analysed by flow cytometry (BD FACSCanto II).

Osteoblastic differentiation of transplanted MSCs. As a non-differentiated

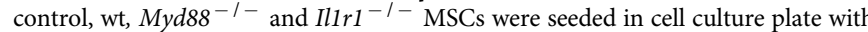
$\alpha$-MEM containing $10 \%$ FBS for 7 days. At the same time, wt, $M y d 88^{-1-}$ and Illr1 ${ }^{-1-}$ MSCs were labelled with CSFE, transplanted into calvarial defect, and recovered from the defect, as described for the proliferation of transplanted MSCs assay. Cells recovered from the fibrin matrix were sorted using FACS (BD FACSAria II), to isolate CSFE-labelled MSCs. After recovery, MSCs were seeded on 24-well plate at 70-80\% confluency in osteogenesis inducing medium. After 3 and 10 days, total RNAs were isolated and quantitative PCR was performed as described for the osteoblastic differentiation assay.

Mobilization of MSC-like cells. Calvarial defects were treated with fibrin matrix $(40 \mu \mathrm{l})$ containing $1 \mu \mathrm{g}$ of murine PDGF-BB, as described for the calvarial defect model. After 7 days, the partially remodelled fibrinous matrices containing endogenous cells were removed from the defect site and incubated in $1 \mathrm{ml}$ of an enzyme solution as described for the proliferation of transplanted MSCs assay. Isolated cells were stained for $15 \mathrm{~min}$ in $100 \mu \mathrm{l}$ of flow cytometry buffer containing antibodies (Biolegends, 1:200 dilution): anti-mouse CD29, anti-mouse Ly-6 A/E (Sca-1), anti-mouse CD90.1, anti-mouse CD45.2, and anti-mouse CD44. Cells were washed twice with flow cytometry buffer and further analysed by flow cytometry (BD FACSCanto II).

Peptide inhibitor of IL-1R1/MyD88 signalling $\left(\alpha_{\mathbf{2}} \mathbf{P I}_{\mathbf{1}-8}-\mathrm{MyD}_{\mathbf{1}} \mathbf{8}-\mathrm{I}\right)$. The peptide $\alpha_{2} \mathrm{PI}_{1-8}$-MyD88-I (NQEQVSPLVPMSMRGGRQIKIWFQNRRMKWKKRDVLPG TCVNS) was synthesized by GeneScript and verified as $\geq 95.0 \%$ by HPLC. The peptide was further dialyzed against HEPES buffer $(20 \mathrm{mM}$ HEPES, $150 \mathrm{mM} \mathrm{NaCl}$, $\mathrm{pH}$ 7.5). The capacity of the peptide to inhibit IL-1R1/MyD88 signalling was assessed by monitoring the release of cytokines from MSCs following stimulation with murine IL-1 $\beta$. MSCs seeded in 24 -well at $70-80 \%$ confluency were stimulated with $10 \mathrm{ng} \mathrm{ml}^{-1}$ of IL-1 $\beta$ together with $\alpha_{2} \mathrm{PI}_{1-8}-\mathrm{MyD} 88$-I at increasing concentration (1-100 $\mu \mathrm{g} \mathrm{ml}^{-1}$ ). After $24 \mathrm{~h}$, the concentration of IL-6, CCL2, CXCL1 and CXCL2 released were measured using ELISA (Mouse IL-6, CCL2/JE/MCP-1, CXCL1/KC and CXCL2/MIP-2; DuoSets, R\&D Systems). 
MSC delivery system containing inhibitors of IL-1R1/MyD88 signalling. Fibrin matrices with or without wt MSCs were delivered into cranial defects as described for the calvarial defect model $\left(2 \times 10^{6}\right.$ cells per defect). Fibrin matrices $(40 \mu \mathrm{l}$ per defect, $10 \mathrm{mg} \mathrm{ml}^{-1}$ fibrinogen, $2 \mathrm{U} \mathrm{ml}^{-1}$ of thrombin, $5 \mathrm{mM} \mathrm{CaCl}_{2}, 25 \mu \mathrm{g} \mathrm{ml}^{-1}$ aprotinin) were functionalized with $4 \mu \mathrm{g}$ of $\alpha_{2} \mathrm{PI}_{1-8}$-MyD88-I or $1 \mu \mathrm{g}$ of murine IL$1 \mathrm{Ra}$ (R\&D Systems). After 8 weeks, bone regeneration was analysed by microCT as described above.

\section{References}

1. Aurora, A. B. \& Olson, E. N. Immune modulation of stem cells and regeneration. Cell Stem Cell 15, 14-25 (2014).

2. Forbes, S. J. \& Rosenthal, N. Preparing the ground for tissue regeneration: from mechanism to therapy. Nat. Med. 20, 857-869 (2014).

3. Trofin, E. A., Monsarrat, P. \& Kemoun, P. Cell therapy of periodontium: from animal to human? Front. Physiol. 4, 325 (2013).

4. Grayson, W. L. et al. Stromal cells and stem cells in clinical bone regeneration. Nat. Rev. Endocrinol. 11, 140-150 (2015).

5. Neovius, E. \& Engstrand, T. Craniofacial reconstruction with bone and biomaterials: review over the last 11 years. J. Plast. Reconstr. Aesthet. Surg. 63, 1615-1623 (2010).

6. Martino, M. M., Briquez, P. S., Maruyama, K. \& Hubbell, J. A. Extracellular matrix-inspired growth factor delivery systems for bone regeneration. Adv. Drug. Deliv. Rev. 94, 41-52 (2015).

7. Stevens, M. M. Biomaterials for bone tissue engineering. Mater. Today 11, $18-25$ (2008).

8. Martino, M. M. et al. Growth factors engineered for super-affinity to the extracellular matrix enhance tissue healing. Science 343, 885-888 (2014).

9. Jones, E. \& Yang, X. Mesenchymal stem cells and bone regeneration: current status. Injury 42, 562-568 (2011).

10. Piccinini, A. M. \& Midwood, K. S. DAMPening inflammation by modulating TLR signalling. Mediators Inflamm. 2010, 672395 (2010).

11. Chen, G. Y. \& Nunez, G. Sterile inflammation: sensing and reacting to damage. Nat. Rev. Immunol. 10, 826-837 (2010).

12. Kawai, T. \& Akira, S. The role of pattern-recognition receptors in innate immunity: update on Toll-like receptors. Nat. Immunol. 11, 373-384 (2010).

13. Oyama, J. et al. Reduced myocardial ischemia-reperfusion injury in toll-like receptor 4-deficient mice. Circulation 109, 784-789 (2004).

14. Tsung, A. et al. The nuclear factor HMGB1 mediates hepatic injury after murine liver ischemia-reperfusion. J. Exp. Med. 201, 1135-1143 (2005).

15. $\mathrm{Wu}, \mathrm{H}$. et al. TLR4 activation mediates kidney ischemia/reperfusion injury. J. Clin. Invest. 117, 2847-2859 (2007).

16. Tang, S. C. et al. Pivotal role for neuronal Toll-like receptors in ischemic brain injury and functional deficits. Proc. Natl. Acad. Sci. USA 104, 13798-13803 (2007).

17. Bujak, M. et al. Interleukin-1 receptor type I signaling critically regulates infarct healing and cardiac remodeling. Am. J. Pathol. 173, 57-67 (2008).

18. Thomay, A. A. et al. Disruption of interleukin-1 signaling improves the quality of wound healing. Am. J. Pathol. 174, 2129-2136 (2009).

19. Hyakkoku, K. et al. Toll-like receptor 4 (TLR4), but not TLR3 or TLR9, knock-out mice have neuroprotective effects against focal cerebral ischemia. Neuroscience 171, 258-267 (2010).

20. Shichita, T. et al. Peroxiredoxin family proteins are key initiators of post-ischemic inflammation in the brain. Nat. Med. 18, 911-917 (2012).

21. Mirza, R. E., Fang, M. M., Ennis, W. J. \& Koh, T. J. Blocking interleukin-1beta induces a healing-associated wound macrophage phenotype and improves healing in type 2 diabetes. Diabetes 62, 2579-2587 (2013).

22. Bhattacharyya, S. et al. FibronectinEDA promotes chronic cutaneous fibrosis through Toll-like receptor signaling. Sci. Transl. Med. 6, 232ra50 (2014).

23. Takemura, N. et al. Blockade of TLR3 protects mice from lethal radiation-induced gastrointestinal syndrome. Nat. Commun. 5, 3492 (2014),

24. Gomes, P. S. \& Fernandes, M. H. Rodent models in bone-related research: the relevance of calvarial defects in the assessment of bone regeneration strategies. Lab. Anim. 45, 14-24 (2011).

25. Spicer, P. P. et al. Evaluation of bone regeneration using the rat critical size calvarial defect. Nat. Protoc. 7, 1918-1929 (2012).

26. Sims, J. E. \& Smith, D. E. The IL-1 family: regulators of immunity. Nat. Rev. Immunol. 10, 89-102 (2010).

27. Eggenhofer, E. et al. Mesenchymal stem cells are short-lived and do not migrate beyond the lungs after intravenous infusion. Front. Immunol. 3, 297 (2012).

28. Fischer, U. M. et al. Pulmonary passage is a major obstacle for intravenous stem cell delivery: the pulmonary first-pass effect. Stem Cells Dev. 18, 683-692 (2009).

29. Schindeler, A., McDonald, M. M., Bokko, P. \& Little, D. G. Bone remodeling during fracture repair: the cellular picture. Semin. Cell Dev. Biol. 19, 459-466 (2008).

30. Bianco, P. et al. The meaning, the sense and the significance: translating the science of mesenchymal stem cells into medicine. Nat. Med. 19, 35-42 (2013).
31. Zhou, B. O., Yue, R., Murphy, M. M., Peyer, J. G. \& Morrison, S. J. Leptin-receptor-expressing mesenchymal stromal cells represent the main source of bone formed by adult bone marrow. Cell Stem Cell 15, 154-168 (2014).

32. Chan, C. K. et al. Identification and specification of the mouse skeletal stem cell. Cell 160, 285-298 (2015)

33. Worthley, D. L. et al. Gremlin 1 identifies a skeletal stem cell with bone, cartilage, and reticular stromal potential. Cell 160, 269-284 (2015).

34. van Rooijen, N. \& Hendrikx, E. Liposomes for specific depletion of macrophages from organs and tissues. Methods Mol. Biol. 605, 189-203 (2010).

35. Caplan, A. I. \& Correa, D. PDGF in bone formation and regeneration: new insights into a novel mechanism involving MSCs. J. Orthop. Res. 29, 1795-1803 (2011).

36. Long, F. Building strong bones: molecular regulation of the osteoblast lineage. Nat. Rev. Mol. Cell. Biol. 13, 27-38 (2012).

37. Baron, R. \& Kneissel, M. WNT signaling in bone homeostasis and disease: from human mutations to treatments. Nat. Med. 19, 179-192 (2013).

38. Manning, B. D. \& Cantley, L. C. AKT/PKB signaling: navigating downstream. Cell 129, 1261-1274 (2007).

39. Huang, S. M. et al. Tankyrase inhibition stabilizes axin and antagonizes Wnt signalling. Nature 461, 614-620 (2009).

40. Quiniou, C. et al. Development of a novel noncompetitive antagonist of IL-1 receptor. J. Immunol. 180, 6977-6987 (2008).

41. Schense, J. C. \& Hubbell, J. A. Cross-linking exogenous bifunctional peptides into fibrin gels with factor XIIIa. Bioconjug. Chem. 10, 75-81 (1999).

42. Martino, M. M., Briquez, P. S., Ranga, A., Lutolf, M. P. \& Hubbell, J. A. Heparin-binding domain of fibrin(ogen) binds growth factors and promotes tissue repair when incorporated within a synthetic matrix. Proc. Natl Acad. Sci. USA 110, 4563-4568 (2013)

43. Derossi, D., Joliot, A. H., Chassaing, G. \& Prochiantz, A. The third helix of the Antennapedia homeodomain translocates through biological membranes. J. Biol. Chem. 269, 10444-10450 (1994).

44. Hollinger, J. O. \& Kleinschmidt, J. C. The critical size defect as an experimental model to test bone repair materials. J. Craniofac. Surg. 1, 60-68 (1990).

45. Liu, Y. et al. Mesenchymal stem cell-based tissue regeneration is governed by recipient T lymphocytes via IFN-gamma and TNF-alpha. Nat. Med. 17, 1594-1601 (2011).

46. Burzyn, D. et al. A special population of regulatory $\mathrm{T}$ cells potentiates muscle repair. Cell 155, 1282-1295 (2013).

47. Arslan, F. et al. Lack of fibronectin-EDA promotes survival and prevents adverse remodeling and heart function deterioration after myocardial infarction. Circ. Res. 108, 582-592 (2011).

48. Pinho, S. et al. PDGFRalpha and CD51 mark human nestin + sphere-forming mesenchymal stem cells capable of hematopoietic progenitor cell expansion. J. Exp. Med. 210, 1351-1367 (2013).

49. Fernandez-Moure, J. S. et al. Enhanced osteogenic potential of mesenchymal stem cells from cortical bone: a comparative analysis. Stem Cell Res. Ther. 6, 203 (2015).

50. Lv, F. J., Tuan, R. S., Cheung, K. M. \& Leung, V. Y. Concise review: the surface markers and identity of human mesenchymal stem cells. Stem Cells 32, 1408-1419 (2014).

51. Chang, J. et al. NF-kappaB inhibits osteogenic differentiation of mesenchymal stem cells by promoting beta-catenin degradation. Proc. Natl Acad. Sci. USA 110, 9469-9474 (2013).

52. Chen, J., Crawford, R., Chen, C. \& Xiao, Y. The key regulatory roles of the PI3K/Akt signaling pathway in the functionalities of mesenchymal stem cells and applications in tissue regeneration. Tissue. Eng. Part B Rev. 19, 516-528 (2013).

53. Whyte, J. L., Smith, A. A. \& Helms, J. A. Wnt signaling and injury repair. Cold Spring Harb. Perspect. Biol. 4, a008078 (2012).

54. Muschler, G. F., Raut, V. P., Patterson, T. E., Wenke, J. C. \& Hollinger, J. O. The design and use of animal models for translational research in bone tissue engineering and regenerative medicine. Tissue Eng. Part B Rev. 16, 123-145 (2010).

55. Reichert, J. C. et al. A tissue engineering solution for segmental defect regeneration in load-bearing long bones. Sci. Transl. Med. 4, 141 ra93 (2012).

56. Gao, X. et al. A comparison of bone regeneration with human mesenchymal stem cells and muscle-derived stem cells and the critical role of BMP. Biomaterials 35, 6859-6870 (2014).

57. Ratcliffe, E., Glen, K. E., Naing, M. W. \& Williams, D. J. Current status and perspectives on stem cell-based therapies undergoing clinical trials for regenerative medicine: case studies. Br. Med. Bull. 108, 73-94 (2013).

58. Steinert, A. F., Rackwitz, L., Gilbert, F., Noth, U. \& Tuan, R. S. Concise review: the clinical application of mesenchymal stem cells for musculoskeletal regeneration: current status and perspectives. Stem Cells Transl. Med. 1, 237-247 (2012)

59. Kawai, T., Adachi, O., Ogawa, T., Takeda, K. \& Akira, S. Unresponsiveness of MyD88-deficient mice to endotoxin. Immunity 11, 115-122 (1999). 
60. Yamamoto, M. et al. Role of adaptor TRIF in the MyD88-independent toll-like receptor signaling pathway. Science 301, 640-643 (2003).

61. Takeuchi, O. et al. Cutting edge: role of Toll-like receptor 1 in mediating immune response to microbial lipoproteins. J. Immunol. 169, 10-14 (2002).

62. Uematsu, S. et al. Detection of pathogenic intestinal bacteria by Toll-like receptor 5 on intestinal CD11c + lamina propria cells. Nat. Immunol. 7, 868-874 (2006).

63. Hemmi, H. et al. Small anti-viral compounds activate immune cells via the TLR7 MyD88-dependent signaling pathway. Nat. Immunol. 3, 196-200 (2002).

64. Hoshino, K. et al. Cutting edge: Toll-like receptor 4 (TLR4)-deficient mice are hyporesponsive to lipopolysaccharide: evidence for TLR4 as the Lps gene product. J. Immunol. 162, 3749-3752 (1999).

65. Takeuchi, O. et al. Differential roles of TLR2 and TLR4 in recognition of gram-negative and gram-positive bacterial cell wall components. Immunity 11, 443-451 (1999).

66. Hemmi, H. et al. A Toll-like receptor recognizes bacterial DNA. Nature 408, 740-745 (2000).

67. Hildebrand, T., Laib, A., Muller, R., Dequeker, J. \& Ruegsegger, P. Direct three-dimensional morphometric analysis of human cancellous bone: microstructural data from spine, femur, iliac crest, and calcaneus. J. Bone Miner. Res. 14, 1167-1174 (1999).

68. Lutolf, M. P. et al. Repair of bone defects using synthetic mimetics of collagenous extracellular matrices. Nat. Biotechnol. 21, 513-518 (2003).

69. Maruyama, K. et al. Strawberry notch homologue 2 regulates osteoclast fusion by enhancing the expression of DC-STAMP. J. Exp. Med. 210, 1947-1960 (2013).

70. Martino, M. M. et al. Engineering the growth factor microenvironment with fibronectin domains to promote wound and bone tissue healing. Sci. Transl. Med. 3, 100ra89 (2011).

\section{Acknowledgements}

We thank the staff of the Cell Sorting Facility of IFReC (Osaka University) and Scott Stanger from the Institute for Biomechanics (ETH Zurich) for technical assistance as well as E. Kamada for secretarial assistance. This work was funded in part by the Swiss
National Science Foundation (PBELP3-138585, PA00P3-145403 and P300P3-151198) to M.M.M., the Japan Society for the Promotion of Science (JSPS, 15H06348) to M.M.M. the research grant of Astellas Foundation for Research on Metabolic Disorders to M.M.M., the visionary research grant from Takeda Science Foundation to K.M., and a research fellowship for Young Scientists from the Japan Society for the Promotion of Science to K.M.

\section{Author contributions}

M.M.M. designed the research, conducted the majority of the experiments, analysed the data, and wrote the manuscript. K.M. participated to microCT measurements, chimeric mouse generation, osteoblast isolation, and experimental design. G.K. and R.M. participated to microCT measurements and analyses. T.S. and O.T. helped with knockout mouse colonies and experimental design. S.A. supervised the research.

\section{Additional information}

Supplementary Information accompanies this paper at http://www.nature.com/ naturecommunications

Competing financial interests: The authors declare no competing financial interests.

Reprints and permission information is available online at http://npg.nature.com/ reprintsandpermissions/

How to cite this article: Martino, M. M. et al. Inhibition of IL-1R1/MyD88 signalling promotes mesenchymal stem cell-driven tissue regeneration. Nat. Commun. 7:11051 doi: 10.1038/ncomms11051 (2016).

\section{(c) (i)}

This work is licensed under a Creative Commons Attribution 4.0 International License. The images or other third party material in this article are included in the article's Creative Commons license, unless indicated otherwise in the credit line; if the material is not included under the Creative Commons license, users will need to obtain permission from the license holder to reproduce the material. To view a copy of this license, visit http://creativecommons.org/licenses/by/4.0/ 